\title{
El género Panicum (Poaceae: Panicoideae) EN EL NORESTE DE MÉXICO
}

\author{
Jesús Valdés-Reyna ${ }^{1,2}$ Fernando O. Zuloaga 3 , Osvaldo Morrone ${ }^{3}$ y Laura Aragón ${ }^{4}$ \\ 'Departamento de Botánica, Universidad Autónoma Agraria Antonio Narro, \\ Buenavista, 25315, Saltillo, Coahuila, México. \\ ${ }^{3}$ Instituto de Botánica Darwinion, Casilla de Correo 22, B1642HYD, San Isidro, Argentina. \\ ${ }^{4}$ COTECOCA-SAGARPA, Municipio Libre 377, Santa Cruz Atoyac, 03310 México, D.F. \\ ${ }^{2}$ Autor para la correspondencia: Correo-e: jvaldes@uaaan.mx
}

\begin{abstract}
Resumen: Se presenta un estudio taxonómico del género Panicum para el Noreste de México, el cual incluye los estados de Coahuila, Nuevo León y Tamaulipas. La región es considerada un centro de origen y diversificación de plantas de las zonas áridas y semiáridas del país, donde la agricultura y la ganadería son dos actividades muy importantes. El género es el más grande de la tribu Paniceae, con distribución mundial, está representado en el área de estudio por un total de 19 especies con cuatro variedades. Se presenta además una clave para diferenciar los géneros recientemente segregados de Panicum, descripciones de las especies, distribución en México y se incluyen mapas de distribución para el área de estudio.

Palabras clave: Coahuila, Dichanthelium, gramíneas, Hopia, Megathyrsus, Nuevo León Parodiophyllochloa, Steinchisma, Tamaulipas, zacates, Zuloagaea.
\end{abstract}

\begin{abstract}
A taxonomic treatment of the genus Panicum for Northeastern Mexico, which includes the states of Coahuila, Nuevo Leon and Tamaulipas is presented. The area is considered a centre of origin and plant diversification for the arid and semi-arid zones for the country, where the agriculture and livestock activities are important. The genus is the most diverse in tribe Paniceae, with a cosmopolitan distribution, and 19 species are distributed in Northeastern Mexcio. A key to the genera that have been recently segregated from Panicum is presented. In addition, distribution maps are included and species relationships are discussed.
\end{abstract}

Key words: Coahuila, Dichanthelium, grasses, Hopia, Megathyrsus, Nuevo León, Parodiophyllochloa, Steinchisma, Tamaulipas, Zuloagaea.

$\mathbf{E}^{1}$ noreste de México, integrado por los estados de Coahuila, Nuevo León y Tamaulipas (figura 1), cubre una superficie de $291,955 \mathrm{~km}^{2}$, lo cual representa el $15 \%$ de la superficie total del país. Esta zona queda incluida dentro de dos grandes regiones naturales denominadas Desierto Chihuahuense y Tamaulipense, los cuales son considerados como centro de origen y diversificación de muchas especies características de las zonas áridas y semi-áridas del país (Rzedowski, 1994).

Como parte de la revisión de la flora de gramíneas del Noreste de México, se presenta aquí un tratamiento taxonómico que incluye las especies del género Panicum en un área donde la agricultura y ganadería son muy importantes.

Panicum tradicionalmente considerado el mas diverso de las Poaceae (Webster, 1988), incluye aproximadamente 400 especies distribuídas en todo el mundo en regiones tropicales y subtropicales variando en hábitats desde sabanas, pastizales en áreas secas o húmedas, bosques y matorrales, desde el nivel de mar hasta los $2500 \mathrm{~m}$ (Zuloaga, 1987). Panicum fué descrito por Linneo (1753), incluyendo 20 especies y tres formas. Zuloaga (1987) clasificó a las especies de Panicum del Nuevo Mundo, empleando caracteres morfológicos tales como la ornamentación del flósculo superior, tipo de vía fotosintética, caracteres de la espiguilla y número básico de cromosomas. Reconoció seis subgéneros: Panicum, Agrostoides (Hitchc.) Zuloaga, Megathyrsus Pilg., Phanopyrum (Raf.) Pilg., Dichanthelium Hitchc. \& Chase, y Steinchisma (Raf.) Zuloaga.

Estudios filogenéticos recientes, basados en caracteres moleculares y morfológicos, han cuestionado la monofilia de Panicum (Zuloaga et al., 2000; Gómez-Martínez y Culham, 2000; Giussani et al., 2001; Duvall et al., 2001; Aliscioni et 


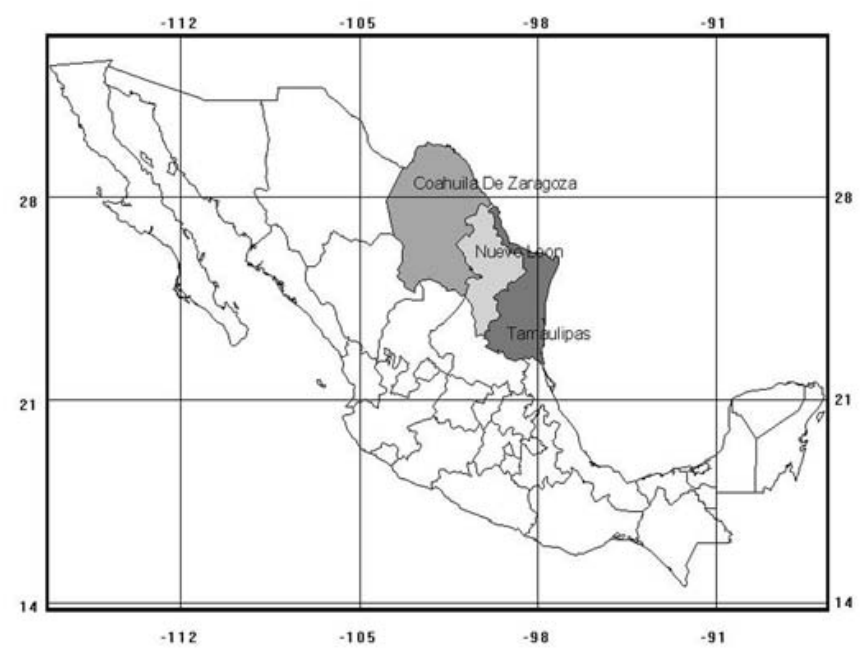

Figura 1. Ubicación del Noreste de México.

al., 2003). Como conclusión, se elevaron a nivel génerico algunos de los subgéneros propuestos por Zuloaga (1987) como Dichanthelium (Hitchc. \& Chase) Gould, Phanopyrum Raf., Steinchisma Raf., y Megathyrsus (Pilg.) B.K. Simon \& S.W.L. Jacobs. A la vez, otros géneros han sido segregados de Panicum: Hopia Zuloaga \& Morrone, Parodiophyllochloa Zuloaga \& Morrone, Cyphonanthus Zuloaga \& Morrone y Zuloagaea (Zuloaga et al., 1998, 2003, 2007; Aliscioni et al., 2003; Freckmann y Lelong, 2003; Simon y Jacobs, 2003; Barkworth, 2004; Bess et al., 2006; Morrone et al., 2008).

El propósito de este estudio es efectuar una revisión de Panicum para el noreste de México, describiendo las especies presentes en el área e incluyendo datos de su distribución. También se presenta una clave para diferenciar a Panicum de sus géneros segregados. El estudio se basó en la revisión de especímenes depositados en los herbarios ANSM, MEXU, UAT, TEX, MO, NMSU, SI y US y se complementó con la consulta de literatura, aportándose nueva información sobre sinónimos y distribución.

Clave de Panicum y géneros afines en el noreste de México

1a. Primera gluma casi tan larga como la segunda; ramificaciones primarias de la panícula generalmente no ramificadas; plantas desarrollando largos rizomas; flósculo superior con micropelos bicelulares hacia el ápice y la base

1b. Primera gluma mucho más corta que la segunda;

Hopia

2a. Lema del flósculo superior finamente rugosa

3a. Culmos usualmente con la base lanosa y con apariencia de cormo

Zuloagaea 3b. Culmos usualmente con la base no lanosa y sin apariencia de cormo

Megathyrsus

2a. Lema del flósculo superior lisa, no rugosa

4a. Pálea del flósculo inferior presente, manifiestamente expandida a la madurez; flósculo superior usualmente con papilas compuestas regularmente distribuidas

Steinchisma

4b. Pálea del flósculo inferior presente o ausente, no expandida a la madurez; flósculo superior liso o con papilas simples o compuestas hacia el ápice

5a. Plantas únicamente con espiguilla casmógamas, sin dimorfismo foliar

\section{Panicum}

6a. Plantas con espiguillas casmógamas y cleistógamas, con o sin dimorfismo foliar

6b. Plantas usualmente con dimorfismo foliar; pálea inferior presente; gluma superior y lemma inferior 7-9 nervadas

Dichanthelium

5b. Plantas sin dimorfismo foliar; pálea inferior ausente; gluma superior y lemma inferior 5-nervadas

Parodiophyllochloa

Panicum L. Sp. pl.: 55. 1753.

Plantas herbáceas anuales o perennes, cespitosas o estoloníferas; culmos huecos, rara vez sólidos, herbáceos a subleñosos, erectos o decumbentes, con o sin rizomas, simples o ramificados; entrenudos y nudos glabros o pilosos; vainas pilosas o glabras, redondeadas, raras veces aquilladas, márgenes hialinos glabros o pilosos; lígulas membránaceas, membranáceo-pilosas o pilosas, ocasionalmente ausentes; seudolígula a veces presente; collar glabro o piloso; láminas generalmente planas, ovadas a lineares, pilosas o glabras, generalmente escábridas, márgenes escabrosos, raras veces lisos. Inflorescencia paniculada rara vez racemosa; ramas primarias verticiladas, alternas u opuestas, adpresas a reflexas; pulvínulos generalmente evidentes, pilosos o glabros; desarticulación por debajo de las glumas; espiguillas globosas a plano-convexas, dorsalmente comprimidas, generalmente sin aristas ni cerdas, raras veces pilosas, solitarias, en pares, ternadas o en grupos pequeños, aglomeradas o separadas entre sí, a veces unilaterales, flósculos 2; gluma inferior y superior generalmente más cortas que la espiguillas, rara vez ausentes o tan largas como la espiguilla, 1-7-nervia, la base generalmente amplexicaule; gluma superior similar a 
la lema inferior y del mismo tamaño que la espiguilla, con 5 a numerosas nervaduras; lema inferior estaminada o neutra; pálea inferior ausente a tan larga como la lema, elíptica a ovada, generalmente hialina, con dos quillas glabras o pilosas y rara vez aladas, ápice bilobado a entero; flósculo superior perfecto, coriáceo o rara vez membranáceo, lanceolado a ovado, piloso o glabro, liso a escabriúsculo principalmente hacia el ápice o base, o a veces transversalmente rugoso, pajizo, amarillo, castaño o negro, a veces con un corto estípite, con los márgenes de la lema enrollados hacia adentro y envolviendo la pálea; lodículas 2, membranáceas; anteras 3, rara vez 2; fruto una cariopsis; hilo generalmente punctiforme u oblongo; embrión tipo panicoide, de un tercio a la mitad del largo de la cariopsis; $\mathrm{x}=9,10$.

Género con alrededor de 400 especies distribuídas principalmente en los trópicos y subtrópicos de ambos hemisferios; para México se reportan 65 especies y para el Noreste de México 19 especies, Se conoce con el nombre común "panizo". La especie tipo es Panicum miliaceum L.

Clave para las especies de Panicum

1a. Gluma inferior una cuarta parte o menos del largo de la espiguilla

2a. Flósculo superior con macropelos unicelulares en toda su superficie

P. trichidiachne

2b. Flósculo superior sin macropelos unicelulares en toda su superficie

\section{P. trichanthum}

1b. Gluma inferior un tercio a casi la totalidad del largo de la espiguilla

3a. Flósculo superior transversalmente rugoso

\section{P. trichoides}

3b. Flósculo superior liso, sin rugososidades

4a. Plantas largamente rizomatosas, con rizomas cundidores, fuertes

5a. Espiguillas de 2.5-3.4 mm de largo, gluma inferior 1/3 a 1/2 del largo de la espiguilla, 3-5-nervia

P. antidotale

5b. Espiguillas de 3.3-7 mm de largo, gluma inferior 1/2 a 4/5 del largo de la espiguilla, 5-9-nervia

6a. Panículas contraídas, con espiguillas aglomeradas sobre las ramificaciones

\section{P. amarum}

6b. Panículas laxas, con espiguillas dispersas sobre las ramificaciones

P. virgatum 4b. Plantas cespitosas, no largamente rizomatosas y sin rizomas cundidores

7a. Gluma inferior truncada, 1/3 o menos del largo de la espiguilla

P. coloratum

7b. Gluma inferior aguda, no truncada, 1/3 a 4/5 del largo de la espiguilla

8a. Vainas aquilladas, flósculo superior con dos aguijones conspicuos en el ápice de la lema

$P$. rigidulum

8b. Vainas no aquilladas, flósculo superior sin aguijones en el ápice de la lema

9a. Inflorescencia una panícula contraída, las ramificaciones de primer orden adpresas a ascendentes

10a. Espiguillas de 3.6-4 mm de largo; flósculo superior con 2 cicatrices en la base de la lema

P. pampinosum

10b. Espiguillas de 5-6 mm de largo; flósculo superior con un anillo circular en la base

P. decolorans

9b. Inflorescencia una panícula abierta o contraída; las ramificaciones de primer orden divaricadas.

11a. Panículas caduca en la madurez por la ruptura del pedúnculo

11b. Panículas persistentes

$$
\text { P. capillare }
$$

12a. Plantas de 1-4 m de altura; vainas hirsutopapilosas con pelos urticantes

P. hirsutum

12b. Plantas 10-130 (-150) cm de altura (largo), vainas glabras a papiloso-híspidas, hirsuto-papilosas o sedoso-papilosas pero los pelos no urticantes.

13a. Plantas perennes

14a. Espiguillas de (3.3-) 3.6-6.5 mm de largo

15a. Espiguillas de 5-6.5 mm de largo; flósculo superior de 3.2-4.5 mm, más corto que la lema inferior

P. capillarioides

15b. Espiguillas de (3.3-) 3.6-4.5 mm de largo; flósculo superior de 0.3-1.5 mm, más corto que la lema superior

16a. Plantas glaucas; láminas basales, rígidas.

P. hallii

16b. Plantas no glaucas; láminas basales no rígidas

P. lepidulum 
14b. Espiguillas de 1.8-3.2 mm de largo 17a. Láminas no glaucas, con pelos seríceos densos en la superficie adaxial y pelos hirsuto-papilosos en la abaxial, las basales no rizadas

$$
\text { P. ghiesbreghtii }
$$

17b. Láminas glaucas, glabras a separadamente hirsutas, las basales rizadas

18a. Espiguillas de 2.1-4 mm de largo; flósculo superior de 0.3$1.2 \mathrm{~mm}$, más corto que la lema inferior; láminas de 6-30 cm de largo por (1-) 2-5 $\mathrm{mm}$ de ancho

\section{P. hallii}

18b. Espiguillas de 1.8-2.2 mm de largo; flósculo superior tan largo como la lema inferior, láminas de (8-) $10-50 \mathrm{~cm}$ de largo por 3-8 $\mathrm{mm}$ de ancho

P. tamaulipense

13b. Plantas anuales

19a. Flósculo superior con un estípite corto y dos prolongaciones cartilaginosas en la base de la lema

P. alatum

19b. Flósculo superior sin estípite ni prolongaciones cartilaginosas

20a. Espiguillas de 4.5-6 $\mathrm{mm}$ de largo; con un entrenudo muy evidente entre la segunda gluma y la lema superior

P. parcum

20b. Espiguilla de 1.9-3.8 $\mathrm{mm}$ de largo; sin entrenudos evidentes entre la segunda gluma y la lema superior

P. hirticaule

1. Panicum alatum Zuloaga \& Morrone. Ann. Missouri Bot. Gard. 83: 224-226. 1996. Tipo: México, Baja California Sur, $15.5 \mathrm{mi} \mathrm{S}$ of El Arco, 27\% $45^{\prime} \mathrm{N}, 113^{\circ} 20^{\prime} \mathrm{W}, 23$ Oct 1959, Wiggins 15160 (holotipo: MO!; isotipos: GH!, MEXU!, LA, SI!).

Plantas cespitosas, con culmos de $13-95 \mathrm{~cm}$ de largo por 1-2 mm de diámetro, erectos a geniculados, ramificados en los nudos inferiores; entrenudos glabros a híspidos en el ápice, huecos; nudos glabros a con pelos cortos; vainas, más cortas que los entrenudos, hirsuto-papilosos con pelos caedizos; lígulas de 0.7-1.8 mm de largo, membranosociliadas; collar glabro o escabroso-piloso; láminas lanceoladas a linear-lanceoladas, de 2-18 cm de largo por 3-17 mm de ancho, planas, glabras o con la superficie abaxial esparcidamente hirsuto-papilosa, base papiloso-ciliada en los márgenes, redondeada a subcordada. Panículas de $3.5-23 \mathrm{~cm}$ de largo, terminales y axilares, laxa-difusas, de subincluidas a exertas, multifloras; ramas primarias de $4.5-12 \mathrm{~cm}$ de largo, de alternas a subopuestas, ascendentes a divaricadas; pulvínulos poco evidentes, glabros; ejes escabrosos, glabros o pilosos en el ápice de los pedicelos; espiguillas elipsoides, de 2.4-3 (-4.5) $\mathrm{mm}$ de largo por 0.7-0.9 (-1.5) $\mathrm{mm}$ de ancho, glabras, adpresas a ascendentes, agudas a acuminadas, en pares muy separados entre sí; gluma inferior de 1.2-1.8 (-2.7) $\mathrm{mm}$ de largo, 1/2 a 3/5 del largo de la espiguilla, 5-7-nervia, ovado-acuminada, separada de la gluma superior por un entrenudo de $0.3 \mathrm{~mm}$ de largo; gluma superior de 2.2-2.7 (-3.3) $\mathrm{mm}$ de largo, 7-9 (-11)-nervia; lema inferior casi igual en tamaño a la segunda gluma, 7-9 (-11)-nervia; flor inferior ausente; pálea inferior ausente o de 0.2-0.9 $\mathrm{mm}$ de largo, $1 / 4$ a 1/2 del largo de la lema inferior, lanceolada, bilobada a aguda, glabra en las quillas; flósculo superior ovoide a obovoide, de 1.5-1.8 (-2.5) mm de largo por 0.6-0.9 (-1.2) $\mathrm{mm}$ de ancho, de 0.7-0.9 (-1.8) mm más corto que la lema inferior, glabro, opaco o brillante, marcadamente papiloso en toda la superficie o sólo en el ápice de la pálea, con un corto estípite y dos prolongaciones cartilaginosas en la base, ápice abruptamente agudo; anteras de $1 \mathrm{~mm}$ de largo, pardas o amarillas; cariopsis de 1-1.2 (-1.7) $\mathrm{mm}$ de largo por 0.6 $(-1) \mathrm{mm}$ de ancho, blanquecina. $\mathrm{n}=9$.

Ecología, distribución y usos: Habita en lugares abiertos, rocosos, ocasionalmente en orillas de arroyos, en lugares húmedos, en suelos arcillosos o arenosos, frecuente en orillas de caminos y localizándose desde el nivel del mar hasta los $1860 \mathrm{~m}$. Se distribuye en el sur de Estados Unidos y México. Para el área de estudio se reporta la variedad típica en Tamaulipas, y la var. minus en Coahuila y Tamaulipas.

Clave para identificar las variedades:

1a Flósculo superior opaco, marcadamente papiloso en toda su superficie

1a. var. alatum

1b Flósculo superior brillante con papilas hacia el ápice de la pálea

1b. var. minus

1a. Panicum alatum Zuloaga \& Morrone var. alatum Material examinado. MÉXICO. BAJA CALIFORNIA SUR: Purísima, 17 Feb 1889, Brandegee 8 (LA, US); $12 \mathrm{mi}$. S of El Solito, 275', $113^{\circ} 48^{\prime} \mathrm{W}, 21$ Oct 1959, Wiggins 15135 (MEX, MO); 11 mi. S of Millers landing, 19 Oct 1959, Wiggins 15097 (GH, ISC); $1 \mathrm{mi}$ SW of jct. of road to Huatamote along Hwy. Mex. \# 1, 365 m, 29 Ene 1977, Reeder \& Reeder 6718 (MEXU); Cuesta 
de Chuenque, ca. $22 \mathrm{~km}$ south of Loreto on road to Puerto Escondido, $25^{\circ} 51^{\prime} \mathrm{N}, 111^{\circ} 25^{\prime} \mathrm{W}, 10$ Oct 1964 , Carter \& Ferris 4726 (LA, MEXU). DURANGO: Ceballos, Zona del Silencio, 1050 m, 25 Oct 1978, Martínez 1313 (MEXU). GUERRERO: Distrito Coyuca, Cutzamala, 8 Sep 1934, Hinton et al. 6423 (GH, NY, US); Cutzamala, 8 Sep 1934, Hinton 6423 (GH, MO). MICHOACAN: Apatzingán, 4 mi W of Apatzingán, 1200 ft, 8 Ago 1941, Leavenworth \& Hoogstraal 1371* (MO). NAYARIT: 2 miles southeast of Las Vacas, 60-90 m, 21 Sep 1960, McVaugh 19291 (US). SAN LUIS POTOSÍ: 12 miles east of Ciudad Valles, 17 Jul 1963, McGregor et al. 840 (US); two km E of Santa Catarina along Hwy. 70, 1220 m, 23 Oct 1978, Reeder \& Reeder 7045 (LA). SINALOA: El Quelite cutt-off to Rt. 15, $34 \mathrm{mi}$. S of Elota, $10 \mathrm{Sep}$ 1962, Skorepa 116 (MO, WIS), pr. p.; Cerros Navachiste, about Bahía Topolobampo, 26/30 Sep 1954, Gentry 14353 (MEXU, SI); outskirts of Topolobampo, 9.10.1966, 9 Oct 1966, Gould 12110 (GH, US). SONORA: 54.5 mi. S of Hermosillo, 21 Sep 1974, de Wet \& Harlan 4354 (MEXU, MO); $35.8 \mathrm{mi}$ SE of Guaymas along Mex. 15/22 Sep 1974, de Wet \& Harlan 4732 (MEXU); Guaymas, 17 Sep 1908, Hitchcock 3553 (US), 1887, Palmer 208 (LA, NY, US), 346 (US); near Guaymas, on rocky, brush-covered slopes just north of Miramar Beach, 7 Oct 1966, Gould 12071 (LA). TAMAULIPAS: between Cerro Mante y Tampico village of Granja Trinidad, 31 Ago 1971, Beetle et al. M-1211 (ISC, MO). Sin localidad, 1897, Palmer 249 (US), 251 (GH, US) (figura 2).

1b. Panicum alatum Zuloaga \& Morrone var. minus (Andersson) Zuloaga \& Morrone, Ann. Missouri Bot. Gard. 83: 226-227. 1996.

Panicum hirticaule var. minus Andersson, Kongl. Svensk. Vetensk. Acad. Handl. 1853: 135, 1855. Tipo: México, Sinaloa, Culiacán, 27 Ago/15 Sep 1891, Palmer 1545 (holotipo: NY; isotipos: LA, SI, W).

Ecología, distribución y usos: Habita en suelos rocosos, arcillosos o arenosos, común a lo largo de bordes de caminos desde nivel del mar hasta los $1860 \mathrm{~m}$. Ampliamente distríbuida en el sur de los Estados Unidos y norte de México, llegando hasta Sudamérica.

Material examinado: MÉXICO. BAJA CALIFORNIA: Sierra Juárez, 2 Oct 1966, Moran 13664 (MO). BAJA CALIFORNIA SUR: San José del Cabo, 17 Oct 1899, Brandegee 42 (LA, US); Llano Caquihui, Sierra de la Giganta west of Los Dolores, $24^{\circ}$ 26’ N, $110^{\circ} 52^{\prime} \mathrm{W}, 17$ Nov 1959, Wiggins $15510(\mathrm{GH})$; 3.3 miles southwest of San Ignacio, $27^{\circ} 14^{\prime} \mathrm{N}, 112^{\circ} 53^{\prime} \mathrm{W}, 25$ Oct 1959 , Wiggins 15179 (LA); Sierra de la Giganta, Arroyo at norhwest base of Cerro Mechudo, 24 48’ N, 110 44'W, 2 Nov 1971, Moran 18878 1/2 (LA). CAMPECHE: on W edge of Escárcega in disturbed area, 21 Dic 1972, Reeder \& Reeder 6098 (MO). CHIAPAS: Chiapa de Corzo, El Chorredero 5.6 miles east of Chiapa de Corzo along Mexican highway 190, 2500 ft, 21 Jun 1966, Laughlin 1113 (US); Mun. Tuxtla Gutierrez, 1800 ft, 1 Jul 1965, Breedlove 10630 (US); about 27 miles northwest of Mexico-Guatemala border on the road to Comitán, 900 m, 23 Ago 1953, Reeder \& Reeder 2082 (LA, MEXU). CHIHUAHUA: Chihuahua, $4800 \mathrm{ft}$, Soderstrom 896 (US); Meoquí, 24 Ago 1935, Le Sueur 032 (US); Llano de Chilicote 7 miles east of Chilicote Station, 26 Sep 1938, Johnston
7992*** (GH, US). COAHUILA: El Mesteño, Ejido 4 de Marzo, 28 Jul 1976, Roig s.n. (ANSM). GUERRERO: 6 km al W de Colotlipa, 20 Ago 1978, Blanco et al. 512 (MEXU). JALISCO: Guadalajara, Río Grande de santiago, 27 km E of Guadalajara, 5200 ft, 26 Ago 1941, Leavenworth \& Leavenworth 1875 (MO); Puente Grande, 13 miles SE of Guadalajara, on road to Aguascalientes, 5000 ft, 17 Sep 1959, Soderstrom 647 (US); Tecolotlán, 1500 m, 5 Oct 1970, Díaz Luna 2044 (MEXU). MICHOACÁN: Apatzingán, jungle at La Majada, 5 miles west of Apatzingán, 1000 m, 5 Ago 1941, Leavenworth \& Leavenworth 1335 (US); Chavinda, 27 Sep 1946, Hernández Xolocotzi et al. X-2791 (US); ca. 5 miles north of Cotija and 22 miles south of Jiquilpán, 6000-6200 ft, King \& Soderstrom 4679 (LA, NY, US). MORELOS: $2 \mathrm{~km} \mathrm{NW}$ of Axochiapan, 10 Ago 1950, Walther 63 (US); $12 \mathrm{~km} \mathrm{NW}$ of Axochiapan, $3500 \mathrm{ft}, 10$ Ago 1950, Lyons Jr. 59 (US), 83 (MEXU, US). OAXACA: Tomellin, 14 Ago 1910, Hitchcock s.n., Amer. Gr. Hb. 28 (LA, US); $12 \mathrm{~km}$ northeast of the city of Tehuantepec, along the Pan-American highway (routes 185 \& 190), 50 m, 7 Jul 1958, King 391 (MEXU, US). SAN LUIS POTOSÍ: Palma Court, Valles, 8 Ago 1961, Gould 9558 (ISC, LA, MO, US). SINALOA: about 15 miles southeast of Villa Unión, in disturbed area along the road, 23 Sep 1953, 90 m, Reeder \& Reeder 2430 (LA, MEXU, US); vicinity of Labradas, 18 sep 1925, Ferris \& Mexía 5070 (MEXU); sin localidad, 27 Ago 1891, Palmer 1554 (F, NY). SONORA: 10 miles south of Hermosillo, 17 Sep 1908, Hitchcock 3541 (US); Hermosillo, 17 Sep 1908, Hitchcock 3573 (US); Guaymas, 17 Sep 1908, Hitchcock 3547 (US); Alamos, 16/30 Sep 1890, Palmer 750 (GH, US); Pinacate Región, llanuras al noroeste del Sierra Blanca, 3133 N, 113 27W, 30 Oct 1982, Ezcurra s.n. (MEXU 487793); Pinacate Junction, Pinacate Region, $7.5 \mathrm{~km}$ East of Los Vidrios, 3159 N, 11321 W, 215 m, 14 Sep 1986, Felger 86-339 (MEXU). TAMAULIPAS: en los alrededores de Ciudad Mante, SánchezKen \& Nieto M. 430 (MEXU). VERACRUZ: Puente Nacional Veracruz, carretera Jalapa-Veracruz, Emiliano Zapata, 250 m, 10 Ago 1982, Dorantes et al. 1510 (F, MEXU) (figura 2).

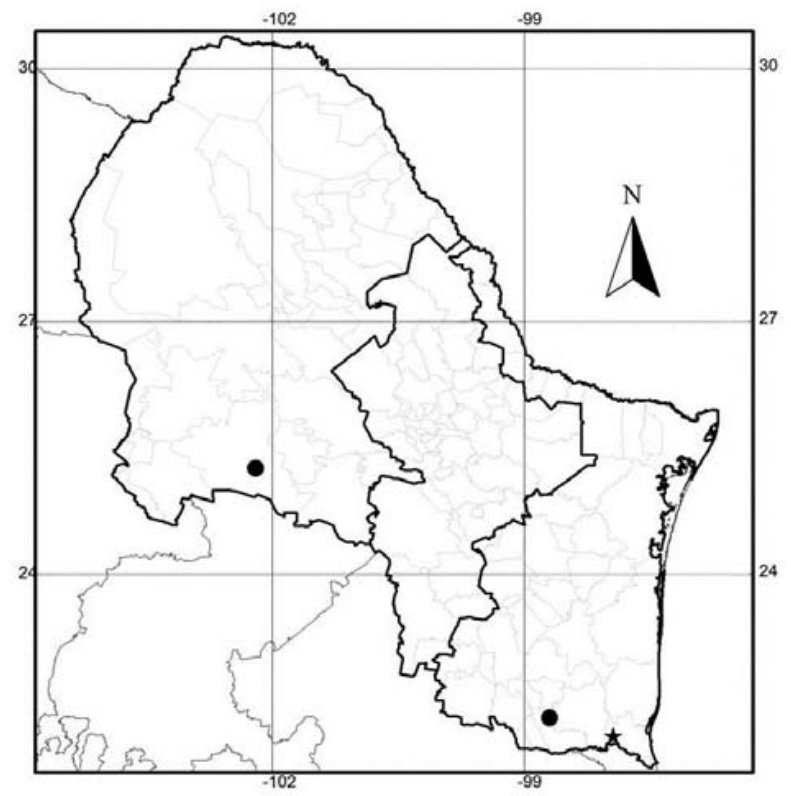

Figura 2. Distribución de $\star$ Panicum alatum var. alatum $\mathrm{y} \bullet P$. alatum var. minus en el Noreste de México. 
2. Panicum amarum Elliott, Sketch Bot. S. Carolina 1:121. 1816. Tipo: Estados Unidos, South Carolina, among the sandhills on the seashore, S. Elliott s.n. (lectotipo: PH; isolectotipo: US-80454!, fragmento ex PH).

Plantas perennes, fuertemente rizomatosas, con culmos cespitosos de 0.3-2 (-3) $\mathrm{m}$ de largo por 3-8 $\mathrm{mm}$ de ancho, simples a ramificados en los nudos inferiores y medios; entrenudos subleñosos a leñosos, huecos, glabros, erectos a decumbentes; nudos engrosados, glabros, castaños; vainas más largas o más cortas que los entrenudos, glabras o cortamente pilosas hacia los márgenes superiores, redondeadas; lígulas membranáceo-ciliadas, de 1.1-4.2 mm de largo, la porción membranácea reducidas, de 0.3-0.5 mm long; collar castaño, glabro; láminas linear-lanceoladas, de $7-50 \mathrm{~cm}$ de largo por 3-17 $\mathrm{mm}$ de ancho, planas en la base e involutas hacia el ápice, glabras o pilosas en la base de la superficie adaxial, a veces esparcidamente papilosas en los márgenes, de base redondeada y ápice largamente subulado. Panículas de 10-45 (-50) cm de largo por ca. $3 \mathrm{~cm}$ de ancho, terminales, contraídas, cortamente exertas o parcialmente incluídas en las hojas superiores; pedúnculo cilíndrico, glabro; eje principal anguloso, glabro, pulvínulos glabros; ramificaciones de primer orden de 4-19 cm de largo, alternas a subopuestas, ascendentes o adpresas, ejes de las ramificaciones y pedicelos triquetros, escabriúsculos, espiguillas congestas sobre ejes cortos de tercer o cuarto orden; espiguillas angostamente ovoides, de 5.2-7.7 mm de largo por (1.5-) 1.7$2 \mathrm{~mm}$ de ancho, biconvexas, pajizas o con tintes violáceos, glabras, gluma superior y lema inferior subiguales, superando en largo al flósculo superior, acuminadas, con nervios manifiestos; gluma inferior de 4.4-5 mm de largo, 3/4 a 4/5 del largo de la espiguilla, 5-9-nervia, débil o fuertemente ner-

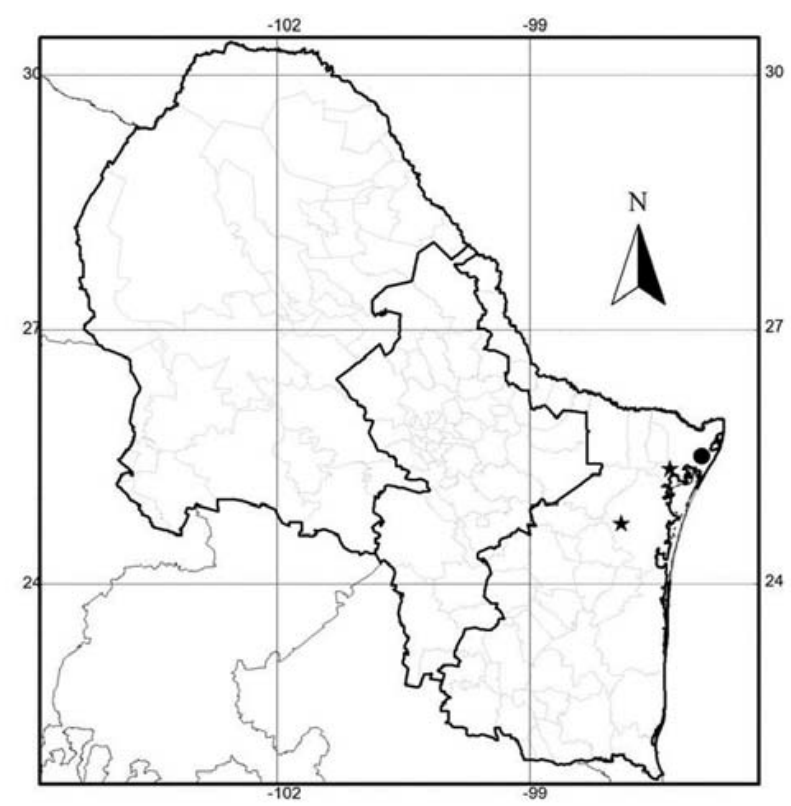

Figura 3. Distribución de $\star$ Panicum amarum var. amarulum y - P. amarum var. amarum en el Noreste de México. vada, acuminada, cortamente pilosa en la cara interna; gluma superior 7-9-nervia; lema inferior ligeramente más corta que la segunda gluma, 7-9-nervia; estambres 3, anteras de 2.6-2.7 $\mathrm{mm}$ de largo; pálea inferior largamente elíptica, de 4-7 mm de largo, 4/5 del largo de la lema inferior, hialina, de ápice agudo y entero, quillas glabras o escasamente ciliadas, flor inferior estaminada, estambres 3, lodículas 2; flósculo superior angostamente ovoide o de contorno oblongo, de 3.2-3.9 $\mathrm{mm}$ de largo por 1-1.8 $\mathrm{mm}$ de ancho, glabro y liso, endurecido, angostamente ovado u oblongo, subagudo, decíduo a la madurez, con papilas verrugosas hacia el ápice de la pálea; lema 5-nervia; estambres 3 , anteras de 1.8-2.2 mm de largo; lodículas 2 , conduplicadas, $0.5 \mathrm{~mm}$ long; cariopsis no vista.

Clave para identificar las variedades:

1a Espiguillas de 5.2-7.7 $\mathrm{mm}$ de largo

2a. var. amarum

1b Espiguillas de 4.4-5.1 $\mathrm{mm}$ de largo

2b. var. amarulum

\section{2a. Panicum amarum Elliott var. amarum}

Ecología, distribución y usos: Habita en dunas costeras desde los Estados hasta Campeche.

Material examinado: MÉXICO. CAMPECHE: km 11 de Isla Aguada, 1 Abr 1982, Brigada de dunas 577 (MEXU). TABASCO: Chiltepec, Ene 1964, Barlow 12/7A (MEXU). TAMAULIPAS: Playa Bagdad, $16 \mathrm{~km}$ al norte de Playa Lauro Villar, vegetación de dunas costeras, 13 Feb 1985, Baro 633 (MO). VERACRUZ: Tecolutla, Dic 1973, Boege 3004 (MEXU) (figura 3).

2b. Panicum amarum Elliott var. amarulum (Hitchc. \& Chase) P. Palmer, Brittonia 27:149. 1975. Panicum amarulum Hitchc. et Chase, Contr. U.S. Natl. Herb. 15:96. 1910. Tipo: Estados Unidos, Virginia, Virginia Beach, 24 Sep 1900, T.A. Williams 3090 (holotipo: US-592748!).

Ecología, distribución y usos: Crece en ambientes similares a los de la variedad típica. Distribuída desde Estados Unidos hasta Belice y en el Caribe.

Material examinado: MÉXICO. CAMPECHE: $40 \mathrm{~km}$ W of Isla Aguada, Saver et al. 3350 (US). QUINTANA ROO: Isla Mujeres, near north end of island, Sauer \& Gade 3264 (US); camino rumbo a Punta Molas, 20 29'N, 86 50’W, 28 Ago 1985, Ortíz 900 (MO); Puerto Morelos, herbácea de $1 \mathrm{~m}$ de alto, duna costera, 7 Sep 1982, Cabrera 3476 (MEXU, MO); a $5 \mathrm{~km}$ al S de la zona urbana de Isla de Mujeres, a $2 \mathrm{~km}$ al $\mathrm{N}$ del Parque Natural El Garrafón, 18 Sep 1985, Cabrera \& Cabrera 9236 (MO); $2 \mathrm{~km}$ al S de las ruinas de Tulum, vegetación de dunas costeras, 16 Sep 1979, Quero et al. 2855 (MO); Punta Nizuc, a $11 \mathrm{~km}$ al Este del aeropuerto de Cancún, 31 Ago 1980, Sousa 11219 (MEXU). TAMAULIPAS: El Mezquital, $61 \mathrm{~km}$ al Este de la carretera a Matamoros, suelo arcilloso-arenoso, 3 Oct 1984, Baro 513 (MEXU, MO). YUCATÁN: $3 \mathrm{~km}$ al W de Sisal, hacia Celestun por el camino costero antiguo, 2010 N, 9005 W, 12 Nov 1981, Espejel et al. 331 (MEXU) (figura 3). 
3. Panicum antidotale Retz., Observ. Bot. 4: 17. 1786. Tipo: Colitur in hortis Malabarorum, König s.n. (holotipo: LD, no visto; isotipos: K, US!).

Planta perenne, rizomatosa, con culmos de (0.4-) 0.5-3 m de largo por 2 a 4 (-6) $\mathrm{mm}$ de diámetro, subleñosos, erectos o geniculados y decumbentes en los nudos inferiores, a veces decumbentes, simples o ramificados; entrenudos de 4$10 \mathrm{~cm}$ de largo, macizos, glabros, pruinosos principalmente hacia los nudos; nudos glabros o pubescentes, engrosados, castaños; vainas iguales o más cortas que los entrenudos, de 4-7 cm de largo, glabras u ocasionalmente papiloso-pilosas, redondeadas, los márgenes membranáceos; lígulas membranáceo-ciliadas, de 0.5-1.4 mm de largo; collar glabro o puberulento, castaño; láminas lineares, de 10-60 cm de largo por (3-) 4-20 $\mathrm{mm}$ de ancho, planas, lineares, glabras, ocasionalmente papilosas principalmente cerca de la base, o puberulentas, de base redondeada a angosta, los márgenes membranáceos. Panículas terminales de 10-45 cm de largo, 5-20 cm de ancho, exertas, laxas o a veces contraídas, multifloras; eje principal anguloso, escabroso a liso, pulvínulos cortamente pilosos, ramificaciones de primer orden de 4-12 $\mathrm{cm}$ de largo, pseudoverticiladas a opuestas o alternas, ascendentes, espiguillas aglomeradas sobre las ramas, pedicelos de 0.7-3 mm de largo, escabriúsculos, con cortos pelos gruesos o sin los mismos; espiguillas de 2.5-3.4 mm de largo por 0.8-1.1 (-1.3) $\mathrm{mm}$ de ancho, largamente ovoides, glabras, pajizas a castañas y con tintes violáceos, glumas y lema inferior con nervios marcados y escábridas en la cara interna; gluma inferior ovada, de 1.4-2.2 mm de largo, 1/3 a 1/2 del largo de la espiguilla, 3-5-nervia, aguda u obtusa; gluma superior de 2.1-3 mm de largo, 5-9-nervia; lema inferior de 2.4-3.2 mm de largo, aguda, igual o un poco más larga que la lema superior, 5-9-nervia; pálea inferior de 2.2-3 mm de largo, $0.7-1 \mathrm{~mm}$ de ancho, 4/5 del tamaño de la lema inferior, elíptico-lanceolada, de ápice agudo y entero, las quillas glabras; flor inferior estaminada, anteras ca. $1.4 \mathrm{~mm}$ de largo; flósculo superior ovoide, de 1.8-2.8 mm de largo por 0.9-1.1 $\mathrm{mm}$ de ancho, glabro, liso, agudo, con manchas obscuras al madurar; anteras hasta de $1.6 \mathrm{~mm}$ de largo, pardas; cariopsis de 1.5-1.9 mm de largo por 0.8-1.1 mm de ancho, blanca o parda; hilo punctiforme, embrión $1 / 2$ o poco más de la mitad de la cariopsis. $n=9,14$.

Ecología, disribución y usos: Habita en dunas a lo largo de los ríos, en zonas desérticas, potreros y orillas de caminos, desde el nivel del mar hasta los $1200 \mathrm{~m}$. Florece de abril a noviembre o diciembre. Especie de Australia y Asia, descrita originalmente para India; introducida en América, encóntrandose desde Estados Unidos hasta Sudamérica, en Argentina. Es una especie resistente a la sequía y se usa para combatir la erosión, además es altamente palatable y consumida por el ganado y ovejas.

\section{Nombre común: "panizo azul"}

Material examinado: MÉXICO. BAJA CALIFORNIA: Seven miles NNW of Chapala on a rocky slope, $760 \mathrm{~m}$, Reeder \& Reeder 7178 (US). COAHUILA: Terrenos de la U.A.A.A.N., Buenavista, Saltillo, 24 Sep 1982, Villarreal 1772 (ANSM, MEXU) (figura 4).

4. Panicum capillare L., Sp. Pl. 1: 58. 1753. Tipo: Estados Unidos, Virginia, sin localidad, Clayton 454 (lectotipo: BM designado por Hitchcock \& Chase, 1910, isotipo: US80553!, fragmento ex BM).

Plantas anuales, cespitosas, culmos de 0.2-1 m alt., herbáceos, erectas a subgeniculadas en la base, ramificadas en los nudos inferiores y medios; entrenudos cilíndricos de 2.4$6 \mathrm{~cm}$ de largo por 1.5-3 $\mathrm{mm}$ de ancho, huecos, glabros a hirsuto-papilosos principalmente hacia el ápice; nudos violáceos, cubiertos de pelos blanquecinos; vainas más largas que los entrenudos, densamente papiloso-híspidas; lígulas de $0.7-3 \mathrm{~mm}$ de largo, una membrana con pelos; collar hirsuto-pubescente, castaño; láminas linear-lanceoladas, de 5$30 \mathrm{~cm}$ de largo por 4-15 (-25) $\mathrm{mm}$ de ancho, planas, hirsutas o híspidas en una o ambas superficies, de base redondeada a subcordada, bordes escabrosos, los basales con pelos turberculados caducos. Panículas de 13-37 cm de largo, 7-25 cm de ancho, terminales y axilares, las axilares mas pequeñas, laxas, difusas, incluidas a exertas, multifloras, desprendiéndose del culmo en la madurez por ruptura del pedúnculo; pedúnculos largamente exertos, hasta de $30 \mathrm{~cm}$ de largo, pajizos o con tintes violáceos, glabros a esparcidamente pilosos en la región distal; eje principal escabroso, triquetro, densamente híspido en la porción inferior y esparcidamente híspido hacia el ápice de la panoja, pulvínulos pilosos; ramificaciones de primer orden 4-16 cm de largo, alternas a veces opuestas

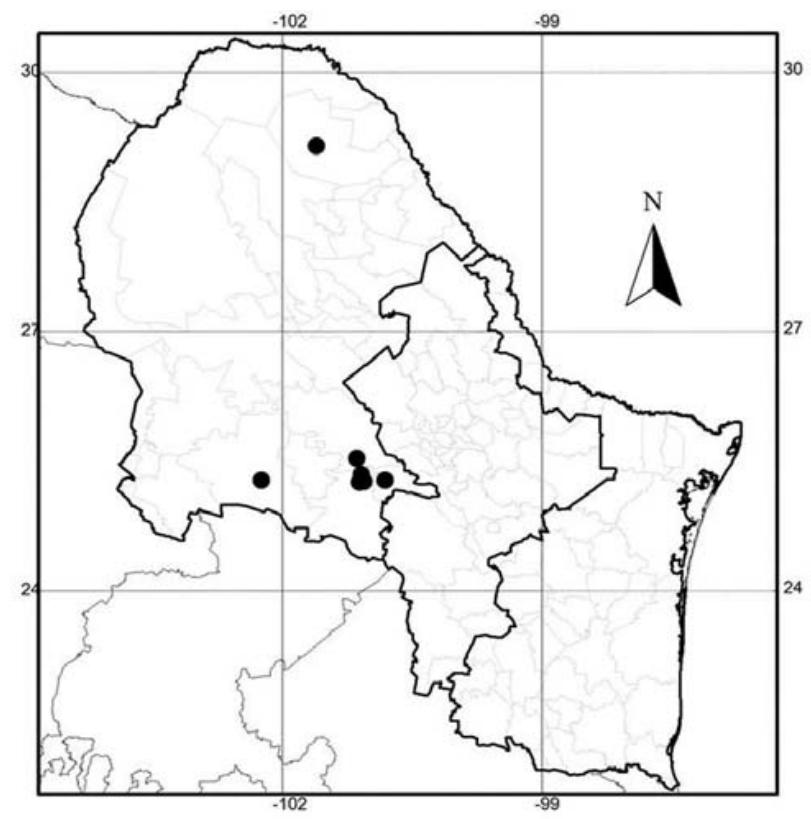

Figura 4. Distribución de $•$ Panicum antidotale en el Noreste de México. 
o verticiladas, divaricadas; pedicelos pilosos, escabrosos, de 0.5-2.7 mm de largo; espiguillas de (1.8-) 2-3.2 mm de largo por $0.5-1 \mathrm{~mm}$ de ancho, elíptico-lanceoladas a ovado-lanceoladas, glabras, agudas a acuminadas, gluma superior y lema inferior subyúgales, superando 0.8-1.2 mm en largo al flósculo superior; gluma inferior de (0.9-) 1.2-1.6 (-1.7) mm de largo, de 1/3 a 1/2 del largo de la espiguilla, 3-7 nervia, generalmente los nervios laterales poco evidentes, aguda a acuminada; gluma superior de 1.8-2.7 (-3.1) mm de largo, 79-nervia; lema inferior glumiforme, 7-9-nervia; pálea inferior ausente o hasta de $0.3 \mathrm{~mm}$ de largo, lanceolada, bilobada, glabra en las quillas, flor inferior ausente; flósculo superior de 1.3-2 mm de largo por 0.5-0.9 mm de ancho, elipsoide, glabro, liso y brillante, agudo, pajizo, castaño a la madurez; estambres 3, anteras de $1 \mathrm{~mm}$ de largo, púrpuras o pardoobscuras; cariopsis anchamente elipsoide, de 1.3-1.6 mm de largo por 0.7-1.1 mm de ancho; hilo punctiforme, embrión $1 / 2$ del largo de la cariopsis. $n=9$.

Ecología, distribución y usos: Se encuentra sobre suelos húmedos, arroyos, tierra de desperdicios, en campos irrigados donde crece como maleza, en tierras de pastoreo y a lo largo de carreteras y caminos, desde el nivel del mar hasta los $2300 \mathrm{~m}$. Florece de marzo a noviembre. Distribuída desde Canadá hasta México y naturalizada en Europa y América del Sur. Se puede encontrar como ornamental o maleza anual de estación de verano.

Nombre común: "zacate brujo".

Material examinado: MÉXICO. BAJA CALIFORNIA: E of San Telmo, Rancho San José, east of San Telmo, 14 Sep 1930, Wiggins \& Demaree 4833 (F, NY, US); banks of Río Santo Domingo, Wiggins \& Demaree 4793 (US); Sierra Juárez, Rancho La Botella, Moran 16483 (US). BAJA CALIFORNIA SUR: La Bocana de Santo Tomas, on Punta Chino road, 31 32N, 116 39W, 20 Sep 1980, Moran 29255 (MEXU). COAHUILA: Municipio de Villa Acuña, Serranías del Burro, Rancho El Bonito, ca. 2901 N, 10207 W, 1620 m, 18 Sep 1977, Valdés Reyna y Riskind 1230 (ANSM), (figura 5.)

5. Panicum capillarioides Vasey in Coulter, Contr. U.S. Natl. Herb. 1: 54. 1890. Tipo: Estados Unidos, Texas, Point Isabel, Nealley 634 (holotipo: US-76925!; probable isotipo: US- 953165!).

Plantas perennes, cespitosas, con culmos de $30-75 \mathrm{~cm}$ de largo por 1-2 (-2.5) mm de diámetro, erectos o ascendentes, frecuentemente torcidos o curvos, simples o ramificados en los nudos inferiores; entrenudos densamente pilosos o glabros, cilíndricos, huecos; nudos pubescentes; vainas iguales o más cortas que los entrenudos, hirsuto-papilosas, los márgenes pestañosos; lígulas membranáceo-ciliadas, de (1-) 1.5 (-2) $\mathrm{mm}$ de largo; pseudolígula ausente o de 2.5-2.7 mm de largo; collar hirsuto-pubescente; láminas linear-lanceoladas de 10-50 cm de largo por 2-12 $\mathrm{mm}$ de ancho, planas, a

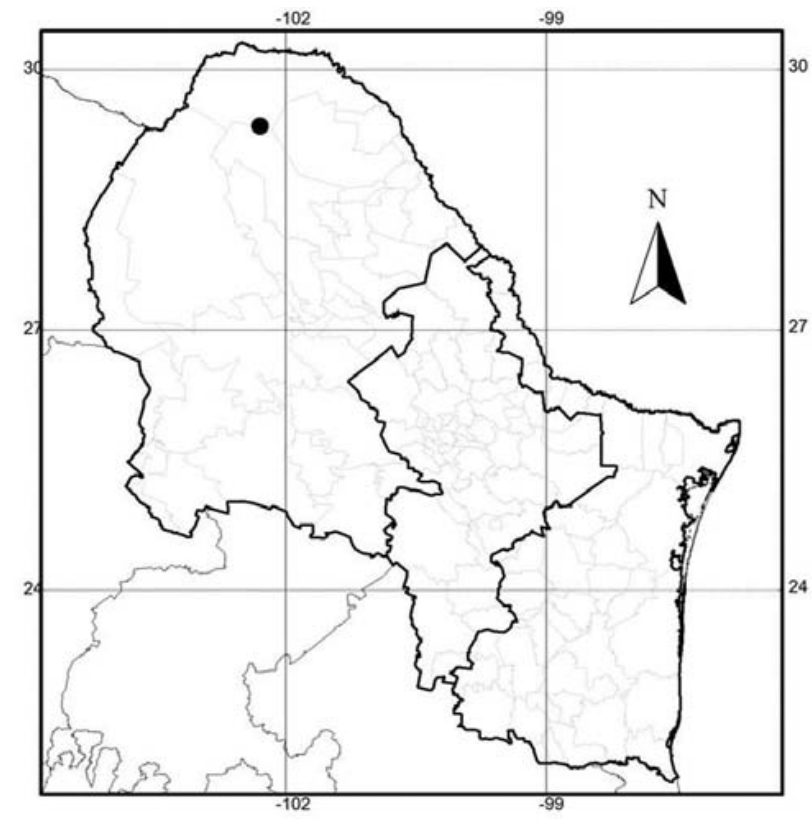

Figura 5. Distribución de - Panicum capillare en el Noreste de México.

veces involutas, hirsuto-papilosas o pilosas a glabrescentes en una o ambas superficies, los márgenes basales con pelos papilosos, de base angosta a redondeada, el ápice atenuado. Panículas de $10-30 \mathrm{~cm}$ de largo, terminales, laxas y difusas, cortamente exertas o subincluidas en las hojas superiores, paucifloras; eje principal anguloso, híspido hacia la base a glabro, escabriúsculo, ramificaciones de primer orden de $8-18 \mathrm{~cm}$ de largo, alternas a subopuestas, las inferiores ocasionalmente subverticiladas, ascendentes a divaricadas; pulvínulos poco evidentes, glabros a cortamente pilosos, ejes de las ramificaciones escabrosos, ramificaciones de segundo orden divergentes, cortas, con 1-2 (-3) espiguillas por ramificación; pedicelos de 2-20 mm de largo; espiguillas largamente ovoides, de 5-6.5 mm de largo por 1-1.2 mm de ancho, glabras, agudas a largamente acuminadas, pajizas y con tintes violáceos, gluma superior y lema inferior subyúgales, superando 3.1-4 mm en largo al flósculo superior; gluma inferior de (2-) 2.5-3 (-3.5) $\mathrm{mm}$ de largo, 1/3 a 1/2 del largo de la espiguilla, 5-7-nervia, aguda a obtusa, separada de la segunda gluma por un entrenudo de casi $0.5 \mathrm{~mm}$ de largo; gluma superior de (4.5-) 5-6 mm de largo, 10-13-nervia; lema inferior glumiforme, aguda, 10-12 nervia; pálea inferior de 1.5-2 (-2.2) $\mathrm{mm}$ de largo, 1/3 del largo de la lema inferior, ovado-lanceolada, bífida, membranácea, quillas con pelos o escábridas; flor inferior ausente; flósculo superior elipsoide a ovoide, de $1.6-2 \mathrm{~mm}$ de largo por $0.8-1.1 \mathrm{~mm}$ de ancho, glabro, liso, brillante, con 2 cicatrices basales de casi $0.2 \mathrm{~mm}$ de largo, agudo; lemma 5-7 nervia, pálea con papilas verrugosas en su ápice; estambres 3 , anteras de 1 $\mathrm{mm}$ de largo, amarillas; cariopsis de (1.3-)1.5 mm de largo 
por (0.6-)1 mm de ancho; hilo oblongo, embrión 1/2 a 3/4 del largo de la cariopsis. $n=18$.

Ecología, distribución y usos: Habita en suelos arenosos cerca de las costas, desde el nivel del mar hasta los $1000 \mathrm{~m}$ de altitud. Florece de abril a diciembre. Se distribuye en el sur de Texas y noreste de México.

Nombre común: "zacate brujo del sur" o "panizo amacollado".

Material examinado: MÉXICO. NUEVO LEÓN: Monterrey, Hitchcock 5547 (US). SAN LUIS POTOSÍ: $10 \mathrm{~km}$ al S de Cárdenas, 1,000 $\mathrm{m}$, Rzedowsky 4618 (US); in a tropical forest between Naranjo-Platinito-Salto de Agua, 400-600 m, Sohns 1430 (US). TAMAULIPAS: Hacienda Buenavista, Wooton s.n. (US-1061806); Chamal, Swallen 1642, 1693 US); sin localidad, 2 Dic 1930, Viereck 857 (US) (figura 6).

6. Panicum coloratum L., Mant. Pl. 1: 30.1767 . Tipo: "Habitat Cairi”, Forsskal s.n. (holotipo: LINN-80.45, no visto).

Plantas perennes, con culmos de (0.5-) 0.6-1.4 m de largo por 1.5-2 (-2.5) $\mathrm{mm}$ de ancho, decumbentes o comúnmente erectos, ocasionalmente geniculados en los nudos inferiores, con rizomas cortos o no desarrollados, simples, no endurecidos y leñosos con la edad; entrenudos glabros, huecos, subleñosos; nudos glabros o puberulentos, los inferiores enraizando; vainas más cortas que los entrenudos, glabras o papiloso-híspidas, redondeadas; lígulas de 0.5-2 $\mathrm{mm}$ de largo, una membrana corta con pelos cortos; collar glabro; láminas linear-lanceoladas, de 7-16 cm de largo por

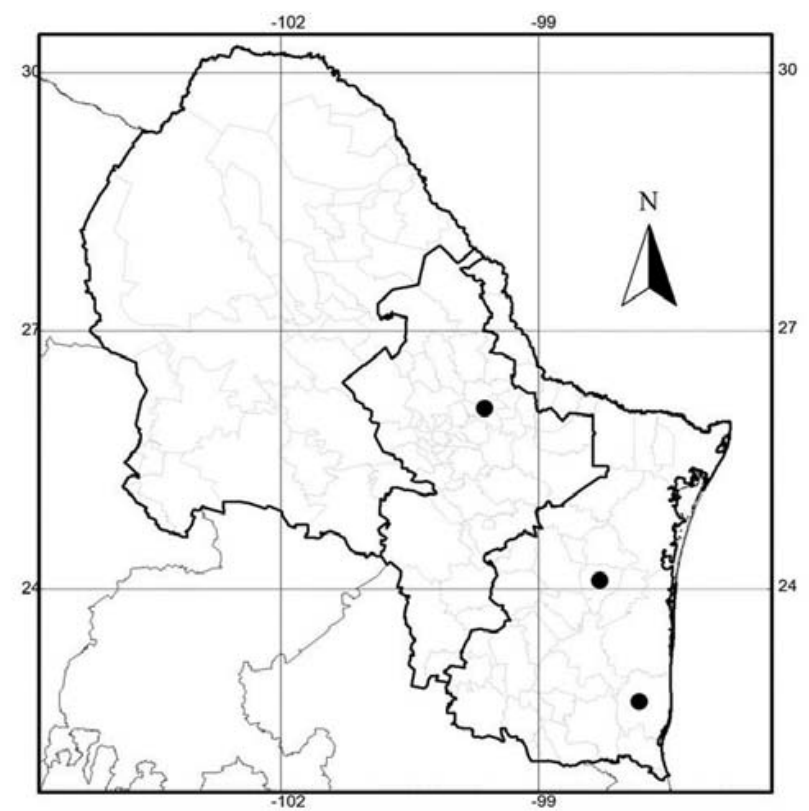

Figura 6. Distribución de Panicum capillaroides en el Noreste de México.
2-6 (-8) mm de ancho, planas, glabras o híspidas en una o ambas superficies, de base subcordada. Panículas de 8-25 $\mathrm{cm}$ de largo, terminales, laxas, exertas, multifloras, ramificaciones de primer orden de 3-14 cm de largo, opuestas y alternas, ascendentes; pulvínulos poco evidentes, glabros; ejes glabros, escabrosos; espiguillas angostamente ovoides a elipsoides, de 2.8-3.2 mm de largo por 1-1.2 mm de ancho, glabras, adpresas a ascendentes, agudas, en pares aglomerados hacia el ápice de las ramas; gluma inferior de 1-1.5 mm de largo, 1/3 del largo de la espiguilla, 1-3-nervia, de ápice truncado, separada de la gluma superior por un corto entrenudo de 0.1-0.3 mm de largo; gluma superior de 2.8-3.1 mm de largo, 5-7-nervia; lema inferior igual o más corta que la gluma superior, 7-nervia; flor inferior estaminada, estambres 3, anteras de 1.5-2 mm de largo; pálea inferior elíptica, de 2.2-2.6 $\mathrm{mm}$ de largo, 4/5 del largo de la lema inferior, diminutamente erosa, quillas glabras; flósculo superior elipsoide, de 2-2.5 mm de largo por 0.8-1 $\mathrm{mm}$ de ancho, glabro, liso y brillante, agudo; estambres 3, anteras de 1.6-1.8 $\mathrm{mm}$ de largo, pardo- amarillentas o pardas; cariopsis de 1.4-1.8 mm de largo por 0.7-1 mm de ancho, blanca. $\mathrm{n}=9,16,18,22$.

Ecología, distribución y usos: Especie escasamente cultivada y ocasionalmente adventicia, se desarrolla en áreas donde la precipitación es menor a los $500 \mathrm{~mm}$ anuales, entre 1900 a 2000 m de altitud. Florece de mayo a octubre. Descrita originalmente de Egipto, introducida en América, desde el sur de los Estados Unidos y México. Representa un buen forraje de las zonas secas, recubre rápidamente el terreno y tiene buena palatabilidad, tanto en forma seca como verde.

\section{Nombre común: "Zacate "klein"}

Material examinado: MÉXICO. NUEVO LEÓN: Rancho Cieneguitas, $5 \mathrm{~km}$ al SE: de Mamulique, 1 Oct 1999. J. Valdes-Reyna VR-2576 y G. Nava (ANSM). COAHUILA: Carretera Progreso- V. Juarez, aproximadamente $8 \mathrm{~km}$ al NE de Progreso. 9 Oct 1996, $J$. A. Villarreal 8523 y J. Zavala (ANSM) (figura 7).

7. Panicum decolorans Kunth, Nov. Gen. Sp. 1: 100. 1815[1816]. Tipo: México, Querétaro, crescit in temperatis, apricis regni Mexicani prope Querétaro, Humboldt s.n. (holotipo: P!; isotipos: P!, US-80663!, fragmento).

Plantas anuales, cespitosas, con culmos erectos de (15-)30$90 \mathrm{~cm}$ de alto, geniculadas o no, simples o ramificadas en los nudos inferiores, panicoide, entrenudos de $6-12 \mathrm{~cm}$ de largo, cilíndricos, huecos, glabros, hirsutos hacia la porción superior a glabrescentes, nudos cortamente pilosos; vainas de $3.5-7 \mathrm{~cm}$ de largo, comúnmente más cortas que los entrenudos, hirsutas, con pelos tuberculados caducos, o glabras, los márgenes cortamente ciliados en toda su superficie o sólo hacia la porción superior, ocasionalmente con un margen ciliado y el restante glabro; lígulas membranáceo-ciliadas, de 0.6-2 mm de largo; cuello glabro; láminas 


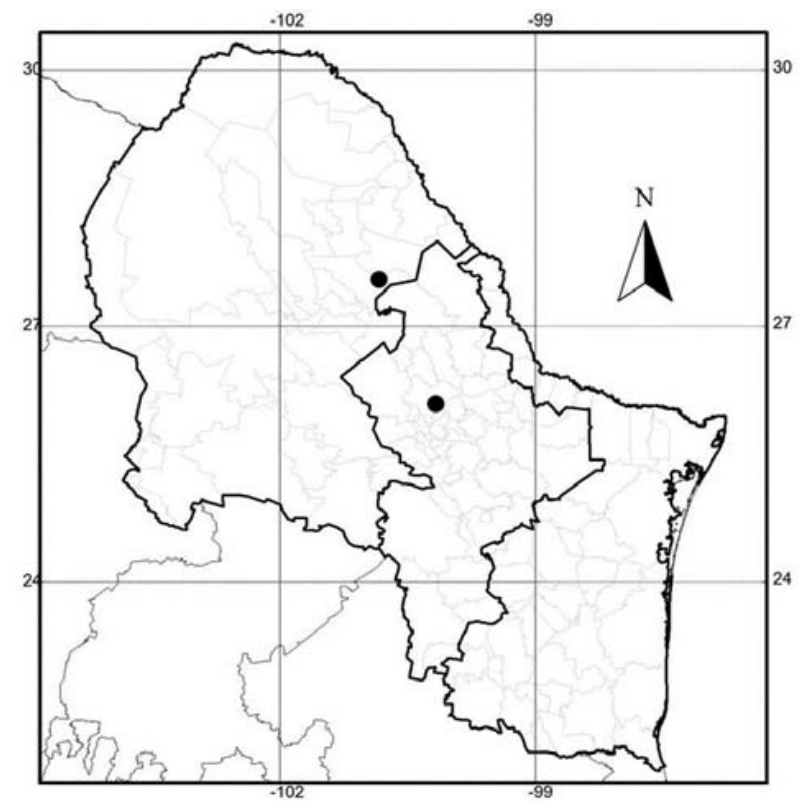

Figura 7. Distribución de • Panicum coloratum en el Noreste de México.

lanceoladas, de $4.5-18 \mathrm{~cm}$ de largo, $0.5-1.5 \mathrm{~cm}$ de ancho, planas, de base redondeada y ápice agudo, glabras a hirsutas en la cara abaxial, ocasionalmente hirsutas en toda la superficie, con pelos tuberculados de 1-1.5 mm de largo, los márgenes basales ciliados con pelos caducos. Panículas terminales exertas, largamente pedunculadas, densas, contraidas, de (5-)10-20 cm de largo, 0.5-1(-2) cm de ancho; eje principal anguloso, escabriúsculo, pulvínulos glabros, ramificaciones de primer orden adpresas al eje, ascendentes, en ocasiones la inferior algo divergente, alternas, con espiguillas congestas sobre ejes de tercer o cuarto orden; pedicelos claviformes, escabrosos, triquetros, de 1.5-4 $\mathrm{mm}$ de largo; espiguillas largamente ovoides, de (4.2-) 5-6 mm de largo, 1.8-2 mm de ancho, glabras, pajizas, con tintes violáceos; gluma superior y lema inferior subiguales o la gluma superior algo menor que la lema inferior, 1-2 mm más largas que el flósculo superior; estípite ausente; gluma inferior ovada, de 1.8-2.7 mm de largo 1/2 o algo menor del largo de la espiguilla, aguda a obtusa, abrazando en la base a la gluma superior, 5-7-nervia, nervio medio escabriúsculo; gluma superior de (3.8-) 5-5.9 mm de largo, aguda a acuminada, 10-13 (-15) nervia, la cara interna escabriúscula hacia el ápice; lema inferior glumiforme, 10-13-nervia; pálea inferior reducida, de 1-1.5 mm de largo, 1/3 o menor del largo del flósculo superior, membránacea, obtusa, glabra; flósculo superior ovoide, de 2.7-3.8 mm de largo por (1.1-) $1.5 \mathrm{~mm}$ de largo, glabro, pajizo a castaño, liso, lustroso, crustáceo, obtuso, fácilmente caedizo a la madurez antes de la caida de las glumas, la base con un anillo circular, castaño a la madurez; lema 7-nervia; pálea con papilas verrugosas hacia el ápice; cariopsis elipsoide, de 2-2.5 mm de largo por 1-1.5 mm de ancho, hilo oblongo, embrión 1/2 a 3/4 del largo de la cariopsis.

Ecología, distribución y usos: Crece desde el nivel del mar hasta los $1870 \mathrm{~m}$. Florece en mayo y noviembre. Endémica de México, en Baja California Sur, Chihuahua, Coahuila, Guanajuato, Hidalgo, Jalisco, Michoacán, Oaxaca, Puebla, Querétaro y San Luis Potosí.

Material examinado. MÉXICO. CHIHUAHUA: $10 \mathrm{~km} \mathrm{~W}$ of Carretas, 1675 m, 21 Ago 1939, Harvey 1578 (GH, US). COAHUILA: Parras, 12 Nov 1935, Archer 3400 (US). GUANAJUATO: Estación El Chico, about $10 \mathrm{~km}$ East of Irapuato, Sohns 210 (US); $39 \mathrm{~km}$ al NE de León, sobre la carretera a San Felipe, 2500 m, bosque de encino, 13 Ago 1990, Rzedowski 49884 (ANSM); Inchamacuaro, Mun. Acambaro, 11 Ago 1985, Rzedowski 38973 (MEXU); $12 \mathrm{~km}$ al N de Salvatierra, sobre la carretera a Cortazar, 18 Sep 1985, Rzedowski 39002 (MEXU). HIDALGO: Mun. Jacala, $4500 \mathrm{ft}$, mountain roadside, Chase 7090 (ANSM, GH, MO, US), 7270 (GH, US). JALISCO: Near Lago Chapala, 12 Ago 1947, Barkley et al. 7639 (F); swampy ground beside Lake Chapala, near Tuxcueca, 4400 ft, 25 Ago 1941, Leavenworth \& Laevenworth 1839 (F, MO, US); 1 mile E of Tuxpán, on Mex 15, 1870 m, 20 Oct 1976, Brunken \& Perino 434 (MEXU, MO). MICHOACÁN: Chavinda, Hernández Xolocotzi et al. 2793 (US); about 13 miles east of Jiquilpan on road from Guadalajara to Morelia, 22 Jul 1950, Reeder et al. 1439 (MEXU). OAXACA: 8 miles W of Huajuapan de León, on road leading to Tehuacán, Puebla, Soderstrom 445 (US); km 568 of Panamerican highway, Baldwin Jr. 14321 (US). PUEBLA: Tehuacán, 5500 ft, 9 Ago 1910, Hitchcock 6057 (US). QUERÉTARO: Querétaro, Hitchcock 5822, 5864 (US), Agniel \& Arsène 10269 (US), Agniel 10393 (US); on rocky slopes back of motel 5 miles N of Querétaro, 8 Sep, Gould 11596 (US); three miles W of Querétaro, Barkley et al. 701 (MEXU, US); vicinity of Querétaro, 1912, Basile 51, 52 (US); de Ciudad de México a Querétaro, km 290, Hernández, Xolocotzi et al. 2304 (US); 6 miles southeast of Queretaro, 2100 m, 12 Ago 1958, Reeder \& Reeder 2975 (MEXU). SAN LUIS POTOSÍ: Cárdenas, Hitchcock 5712 (F, GH, NY, US); Cárdenas, 19 Jul 1910, Hitchcock s.n., Amer. Gr. Nat. Herb. $\mathrm{n}^{\circ} 29$ (MO, US); 2 km E of Santa Catarina along hwy. 70, 1220 m, 23 Oct 1978, Reeder \& Reeder 7042 (MEXU) (figura 8).

8. Panicum ghiesbreghtii E. Fourn., Mexic. Pl. 2: 29. 1886. Tipo: México, Ghiesbreght s.n. (lectotipo: designado por Hitchcock \& Chase, 1910, P!; isolectotipo: US-76924!, fragmento y foto ex P). Panicum hirtivaginum Hitchc. Contr. U.S. Natl. Herb. 12: 223. 1909. Tipo: Cuba: sin localidad, 1865, Wright 758 (holotipo: US-559958!, isotipos: MO!, NY!, P!, US-823614!, 974804!).

Plantas perennes, cespitosas, con culmos de 0.30-0.90 (-1.20) m de largo y 1-2.5 (-3) cm de diámetro, erectos, ascendentes a decumbentes, simples o ramificados en los nudos inferiores; entrenudos de 6-20 cm long, 2-3 mm de diámetro, cilíndricos, huecos, hirsuto-papilosos; nudos pilosos con pelos blanquecinos; vainas de $5-13 \mathrm{~cm}$ de largo, generalmente más cortas que los entrenudos, hirsuto-papilo- 


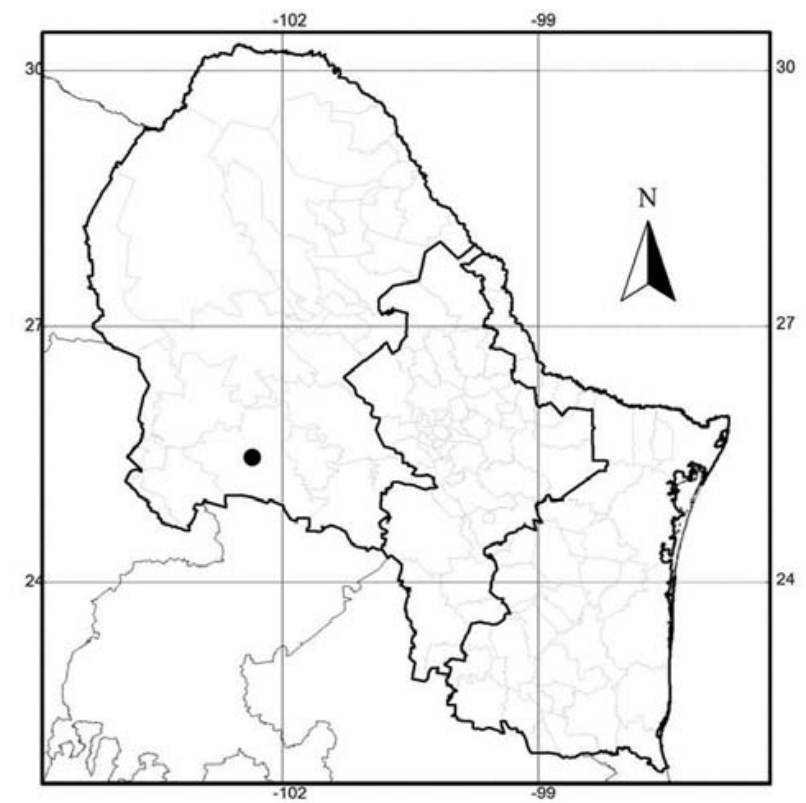

Figura 8. Distribución de - Panicum decolorans en el Noreste de México.

sas; lígulas membranáceo-ciliadas, de (0.5-) 1.2-2 mm de largo, con largos pelos por detrás en la base de la láminas; collar piloso; láminas linear-lanceoladas de 11-30 (-60) cm de largo por (5-) 7-14 mm de ancho, planas, con pelos densos en la superficie adaxial y pelos papiloso-hirsutos en la abaxial, los márgenes basales ciliados, de ápice atenuado y base redondeada. Panículas de 7-35 cm de largo, $5-23 \mathrm{~cm}$ de ancho, terminales y axilares, laxas, difusas, multifloras, subincluidas a exertas, con pedúnculo hasta de $40 \mathrm{~cm}$ de largo; eje principal anguloso, escabrosos, pulvínulos glabros, ramificaciones de primer orden hasta de $22 \mathrm{~cm}$ de largo, alternas, las siguientes verticiladas a opuestas o alternas, divergentes, desnudas en su tercio inferior, espiguillas en pares sobre ejes de tercer orden, ramas primarias hasta de $22 \mathrm{~cm}$ de largo, verticiladas, opuestas o alternas, ascendentes, ejes de las ramificaciones y pedicelos escabrosos; espiguillas largamente ovoides, de 2.6-3.2 mm de largo por 0.9-1.2 $\mathrm{mm}$ de ancho, agudas a acuminadas, verdosas y con tintes violáceos, abiertas a la madurez, gluma superior y lema inferior subyúgales, superando en largo al flósculo superior: gluma inferior de 1.2-1.9 (-2.3) $\mathrm{mm}$ de largo, $1 / 3$ a $1 / 2$ del tamaño de la espiguilla, 5-7-nervia, aguda; gluma superior de 2.5-3.1 mm de largo, 9-13-nervia; lema inferior igual o hasta $0.2 \mathrm{~mm}$ más larga que la gluma superior, 9-11-nervia; pálea inferior de 0.5-1.3 $\mathrm{mm}$ de largo, 0.5-0.8 $\mathrm{mm}$ de ancho, 1/3 a 1/2 del largo de la lema inferior, ovada, obtusa, con quillas glabras, flor inferior ausente; flósculo superior ovoide, de 1.5-2.3 mm de largo por 0.8-1.1 $\mathrm{mm}$ de ancho, (0.3-) 0.5-0.9 mm más corto que la lema inferior, subagudo, obtuso, glabro, liso, crustáceo, con dos cicatrices basales de $0.2 \mathrm{~mm}$ de largo; lema 7-nervia, pálea con papilas simples y micropelos globosos hacia el ápice; estambres 3, anteras de 0.9-1.4 mm de largo, color ámbar o púrpura; cariopsis elipsoide, de 1.2-1.3 mm de largo por 0.7-0.8 $\mathrm{mm}$ de ancho, blanquecina; hilo oblongo, embrión $1 / 2$ del largo de la cariopsis.

Ecología, distribución y usos: Habita en áreas abiertas de bosque caducifolio, de pino, en matorrales o campos de cultivo, hasta los $2400 \mathrm{~m}$ de altitud. Distribuída desde Estados Unidos hasta América del Sur. Es una especie forrajera.

Material examinado: MÉXICO.CAMPECHE: $3 \mathrm{~km}$ al S de Bolonchen de Rejón, cerca de las Grutas de Xtacumbilxunan, por la carretera vía ruinas a Campeche, 25 Jul 1986, Cabrera 11739 (MO); Campo Experimental El Tormento, km 5 carretera Escárcega a Candelaria, 24 Dic 1965, Chavelas \& Quero ES-109 (MEXU). CHIAPAS: ca 22 km SE of Teopisca along Highway 190 to Comitán, pine-oak forest, 2040 m, 11 Ago 1975, Davidse \& Davidse 9492 (MO); grassy flats $3 \mathrm{~km}$ south of Comitán near old airport, 1525 m, 6 Nov 1981, Breedlove \& Davidse 54908 (MEXU, MO); seasonal evergreen forest near new Tuxtla Airport on ridge north and above Ocozocoautla, 1000 m, 12 Nov 1981, Breedlove \& Davidse 55442 (MO). MÉXICO: Peñón, 1700 m, 8 Oct 1933, Hinton 4413 (MO, US); Temascaltepec, near the river, 24 Ago 1932, Hinton 1424 (US), 27 Ago 1932, Hinton 1428 (MEXU). MICHOACÁN: about 12 miles west of Quiroga in open pine-oak forest, 7000-9000 ft, Sohns 791, 797 (US). MORELOS: Oaxtepec, Matuda s.n. (MEXU-288916). OAXACA: Oaxaca, Hitchcock 6143 (US). PUEBLA: Roadside along route 130, 2.7 miles south of the Puebla-Veracruz state line, 20 May 1979, Harriman \& Jansen 15627 (CHAPA). QUINTANA ROO: Coba, in savanna, north of Lake Coba, Jun 1938, Lundell \& Lundell 7791 (F, MEXU, MO, US). SAN LUIS POTOSÍ: Low ground along Río Tampaón, Chase 7480 (GH, US); sin localidad, 1891, Virlet 1306 (SI). SINALOA: Rancho de la Nacha, 25 millas W de Angostura, Vera Santos 1832 (NY). TABASCO: Villahermosa, Archer 3968 (US); Fracc. Los Reyes calle Las Palmas 1 km al W de la carretera Cárdenas-Huimanguillo, 4 Ago 1981, Suárez 4 (MO). TAMAULIPAS: Chamal, Swallen 1717 (US); along route 85, ca. 4-5 miles south of Ciudad Mante, 18 Feb 1961, King 3791 (F, US); 10 km al NW de la desviación a Gómez Farías, 24 Jun 1983, Torres \& Hernández 3097 (MO). VERACRUZ: Río Blanco, near Orizaba, 25 Ago 1910, Hitchcock s.n., Amer. Gr. Hb. 36 (MO, P, US); Orizaba, Hitchock 6363, 6391 (US); environs de Veracruz, Gouin 21 (P); Córdoba, Hitchcock 6418 (US); 1 to 4 km northeast of Campo Experimental de Hule, El Palmar, Zongolica, Vera Santos 2256 (LIL, US); transecto Punta Limón a Cerro Monte de Oro, 20 Jun 1972, Lot et al. 1948 (MEXU); about 5 miles from El Palmar Rubber Exp. Station, growing at edge of a sugar cane field, 95 m, 28 Jul 1953, Reeder \& Reeder 1936 (MEXU); Rancho Alegre, 7 Nov 1970, Chiang 191 (MEXU). YUCATÁN: Chichen Itzá, along roadside, Lundell \& Lundell 7427 (US), Steere 1632 (US), Swalllen 2381 (US), 2404 (MEXU, MO); Uxmal, along trail near ruins, Swallen 2621 (MEXU, US); Izamal, Gaumer 2477 (F, MEXU, US); near Uxmal, 23 Ene 1971, Beetle M-917 (US) (figura 9).

9. Panicum hallii Vasey, Bull. Torrey Bot. Club. 11: 61 . 1884. Tipo: Estados Unidos, Texas, Hall 816 (holotipo: US 76926!; isotipo: NY!). Panicum virletii E. Fourn., Mexic. 


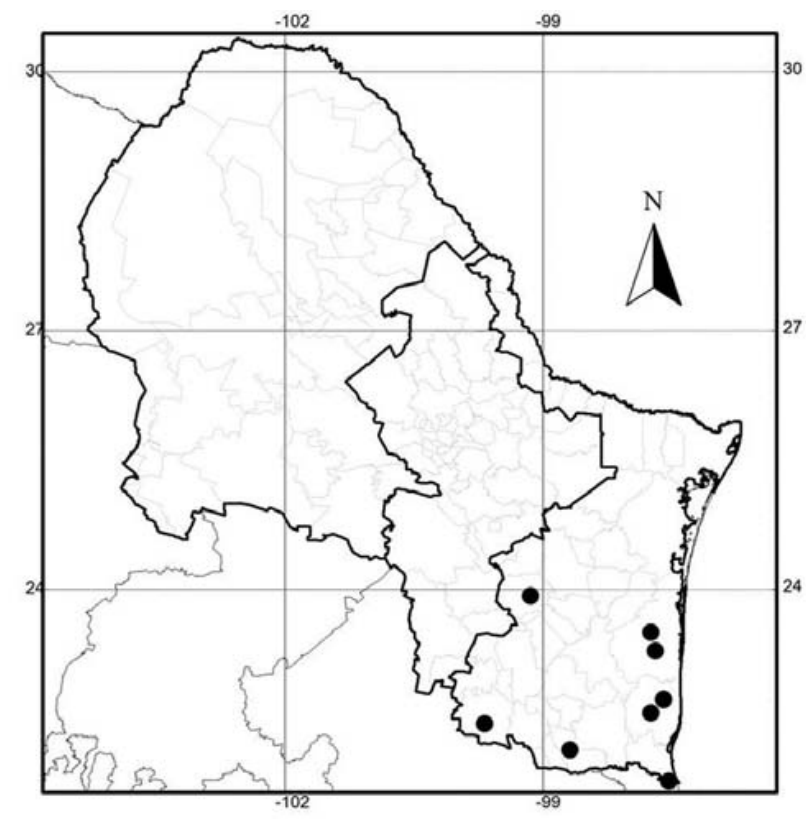

Figura 9. Distribución de - Panicum ghiesbreghtii en el Noreste de México.

Pl. 2: 29. 1886. Tipo: México, San Luis Potosí, M. Virlet 1305 (lectotipo designado por Zuloaga \& Morrone, Ann. Missouri Bot. Gard., 1996, P!; isolectotipo, US-86967!, fragmento ex P).

Plantas perennes, cespitosas, glaucas, con culmos erectos de (10-) 20-75 cm de largo por 1-2 $\mathrm{mm}$ de ancho, simples o ramificados en los nudos inferiores; entrenudos glabros, huecos; nudos con pelos blanquecinos cortos o glabros; vainas de 3-10 cm de largo, generalmente iguales o más largas que los entrenudos, glabras o papiloso-hirsutas, con pelos caedizos, los márgenes membranáceos, glabros o ciliados hacia la porción distal; lígulas de 0.5-1.2 mm de largo, una membrana corta con pelos largos; collar glabro; láminas linear-lanceoladas de 6-30 cm de largo por (1-) 2-5 $\mathrm{mm}$ de ancho, planas o con los márgenes involutos, linearlanceoladas, glabras a esparcidamente hirsutas, glaucas, base con pelos largos y papilosos en los márgenes, angosta a redondeada, láminas basales rizadas. Panículas terminales de 6-31 cm de largo, laxas y difusas, exertas, multifloras; pedúnculos hasta de $40 \mathrm{~cm}$ de largo, cilíndricos, glabros; eje principal triquetro, glabro, pulvínulos glabros; ramificaciones de primer orden de $1-13 \mathrm{~cm}$ de largo, alternas, ascendentes a divaricadas, ejes de las ramificaciones glabros, escabrosos, ramificaciones de segundo orden divergentes o adpresas, pedicelos solitarios o en pares de 1-15 $\mathrm{mm}$ de largo, triquetros, escabriúsculos; espiguillas largamente ovoides, de 2.1-4 mm de largo por 0.8-1.5 mm de ancho, gluma superior y lema inferior subyúgales, 0.3-1.2 $\mathrm{mm}$ más largas que el flósculo superior; gluma inferior de 1.2-2.5 mm de largo, 1/2 a 3/4 del largo de la espiguilla, 3-5-nervia, subaguda a acuminada; gluma superior de 2-3.5 $\mathrm{mm}$ de largo, 7-9 (-11)-nervia; lema inferior glumiforme, 9-11-nervia; pálea inferior de 0.8-1.9 mm de largo, $1 / 2$ a 3/5 del largo de la lema inferior, oblongo- lanceolada, truncada, entera o bilobada, los bordes denticulados; flósculo superior ovoide a elipsoide, de 1.5-2.5 mm de largo por $0.7-1.3 \mathrm{~mm}$ de ancho, crustáceo, glabro, pajizo y con tintes negruzcos a la madurez, con papilas simples en el ápice de la pálea, con 2 cicatrices basales de $0.2 \mathrm{~mm}$ de largo; estambres 3 , anteras de 1-1.5 mm de largo, color pardo, púrpura, ámbar o rojizo; cariopsis ovoide, de 1.2- $1.7 \mathrm{~mm}$ de largo por 0.6-1 mm de ancho, blanquecina; hilo punctiforme, embrión 1/2 del largo de la cariopsis. $n=19$.

Ecología, distribución y usos: Crece comúnmente en matorrales, pastizales o praderas secas de zonas áridas, sobre suelos de lomeríos rocosos y pedregosos; también en suelos irrigados y húmedos, llegando hasta los $2300 \mathrm{~m}$. Florece de marzo a noviembre. Se distribuye en el sur de Estados Unidos y en México. Esta especie tiene uso forrajero, sobre todo porque algunas de sus hojas permanecen verdes gran parte del año. Sus poblaciones se reducen rápidamente bajo sobrepastoreo.

Nombres comunes: "panizo aserrín”, "panizo rizado", "panizo rayado".

\section{Clave para las variedades:}

1 Espiguillas de 2.7-4 mm de largo, adpresas; flósculo superior 0.8-1.2 mm más corto que la lema inferior var. hallii

1 Espiguillas de 2.1-2.8 mm de largo, divaricadas; flósculo superior 0.3- $0.7 \mathrm{~mm}$ más corto que la lema inferior ..var. filipes

\section{Panicum hallii Vasey var. hallii}

Material examinado: MÉXICO. AGUASCALIENTES: $1.5 \mathrm{~km}$ a Real a Asientos, 22 Oct 1965, Atrupo 1723 (MEXU). CHIHUAHUA: km 5 desviación a Nuevo Casas Grandes de carretera Cd. Juárez, 1600 m, 19 Sep 1955, Hernández \& Mathus N-1911 (US); Sierra de Santa Eulalia, $2 \mathrm{~km}$ N of San Antonio, Harvey 1516 (US); camino de Ojinaga a Castillón, Johnston $8175(\mathrm{GH})$; cercanías de rancho El Pino, 10 km SW de Villa Rica, Stewart 2395 (GH); Sta. Eulalia Mountains, Ago 1875, Pringle 376* (F, GH, MO, NY, P, US); base of Cerro Campana, $79 \mathrm{~km} \mathrm{~N}$ of Chihuahua, $1620 \mathrm{~m}$, 23 Ago 1975, Davidse \& Davidse 10057 (MO). COAHUILA: 5 mi S of Piedras Negras, 23.5.1965, Gould 11282 (US); Monclova, in vicinity of Chulavista Hotel, 23.5.1965, Gould 1187 (US); sin localidad, 1880, Palmer 1338 (US, W); 12 miles West of San Buenaventura, 1800 ft, 28 Oct 1964, Reeder \& Reeder 3928 (MEXU); Municipio de Castaños, south of Castaños, Rancho Santa Teresa, Wynd \& Muller 174* (GH, MO, NY, US); Laguna de Jaco, Johnston \& Muller 1111* (GH); 20 miles N of Saltillo, Gould 11796 (GH); 20 miles W of Saltillo, Shreve $9821(\mathrm{GH}) ; 70$ miles W of Saltillo, Wallies 13294 (F, GH); Saltillo, 10/14 Jul 1910, Hitchcock 
5605 (US); San Antonio de los Alamos, eastern base of the volcanic Sierra de San Antonio de los Alamos, Johnston 8250 (US), 8250 a (GH); Sierra de las Cruces, eastern foothills 8 mi. North of Santa Elena Mines, 7 Sep 1940, Johnston \& Muller 1017* (F, GH, US); Sierra del Pino, near La Noria, Johnston \& Muller 467, 694 (GH), Stewart 1211 (GH); Sierra de Santa Rosa, Marsh 1278 (GH); 2 miles NW of Frontera, Ago 1938, Johnston $7170 *(\mathrm{GH})$; 14 mi east of Paila, $400 \mathrm{ft}, 6.9 .1940$, Shreve \& Tinkham 9897 (US); 51 miles northwest of Múzquiz, Gould 11157 (US); La Cuesta del Plomo on the Múzquiz-Boquillas Hwy., 2844'N, 102³1'W, 1750-1775 m, 14 Sep 1972, Chiang et al. 9201 (F, MO); 18 miles south of Sabinas, just north of El Sauz, 18 Oct 1957, Gould \& Morrow 7906 (MO); $11 / 2 \mathrm{~km} \mathrm{~W}$ of Tanque La Mula which is NE of Rancho Piedra Azul, 2909'30'N, 102 35'W, 1275 m, 24 Mar 1973, Johnston et al. 10383 (MEXU, MO). DURANGO: eastern piedmont of Sierra Gamon about Peñón Blanco, 19/20 Sep 1948, 1800-1200 m, Gentry 8349 (US); 24 miles NW of La Zarca, 6200 ft, Soderstrom 819 (US); desert along Hwy. 40, 15 km SW of Pedriceña, 22 Jun 1964, Mick \& Roe 44 (US); just to W of Mexico \#40 at km 221, $26 \mathrm{~km}$ WSW of Torreón, 14 Sep 1978, Iltis et al. 114 (MEXU); 5 km al E de La Joya, Mun. Poanas, 10 Sep 1984, Jimenez 7 (MEXU). HIDALGO: Mun. Jalapa, 500 ft, 1 Jul 1030, Chase 7256 (US); SW of Jacala, $4700 \mathrm{ft}$, Moore Jr. 3924 (GH, US). NUEVO LEÓN: Galeana, Puerto México, carretera 57, 67 km al N de Saltillo, 1600 m, 25 Ago 1978, Bernal \& Cárdenas s.n. (MEXU 271683); orilla del Rio San Juan a $1 \mathrm{~km}$ del poblado San Juan, 230 m, 12 Mar 1986, Garcia y Dominguez 1805 (MEXU); N of Sabinas, Hidalgo, 28 Ago 1971, Beetle 1061 (MO); 34.4 mi. N of Dr. Arroyo on Mex 60, 1560 m, 10 Oct 1976, Brunken \& Perino 241 (MO); N of Monterrey, "La Escondida", 612 m, Roybal 867 (MO, US), 883 (MO, US); Cerca de Monterrey, bancos del Rio Pesqueira, Beetle 1077 (MO); Monterrey, 6/8 Jun 1910, Hitchcock 5537 (US). OAXACA: Mun. Zapotitlan, 4 km al E de Zapotitlan Salinas, 25 Sep 1990, Sánchez-Ken et al. 328 (MEXU); $3 \mathrm{~km}$ al norte de la carretera a Yolotepec, Mun. de San Pedro y San Pablo, 1900 m, 23 Sep 1999, Paz Zambrano y Ramos Marchena 303 (MEXU). PUEBLA: Afueras de Tehuacán, por la carretera a Esperanza, 1 Sep 1989, Chiang et al. 294 (MEXU). QUERETARO: 2 miles S of Querétaro, $6400 \mathrm{ft}$, Soderstrom 531 (US); 3 $\mathrm{km}$ al W de Las Rosas, sobre la carretera a Tequisquiapan, 2000 m, 8 Sep 1990, Rzedowski 50000 (ANSM, MEXU). SAN LUIS POTOSÍ: Valley of the Rioverde Between Rioverde and San Ciro, 850-1000 m, 12 Sep 1954, Sohns 1215 (US); Cárdenas, 19/20 Jul 1910, Hitchcock 57191/2 (US); Charcas, Ago 1934, Whiting 608 (US); 10 km al W de Guadalcazar, 1600 m, Rzedowsky 4931 (GH, US); $8 \mathrm{~km}$ al W de San Lorenzo, km 62 de la Carretera San Luis Potosí a Morelos, Rzedowsky 6869 (GH); Valle de Rioverde, between Rioverde and Boquilla, Sohns 1248 (F, MEXU, P, US); in the Sierra de Guadalcazar between Charco Blanco and Aguaje de García, 1100-1600 m, Sohns 1344 (US); Mun. Charcas, 6 km al E de Laguna Seca, Rzedowski 6547 (US); about $3 \mathrm{~km}$ east of Laguna Seca on the northwestern slopes of the Sierra de Alvarez, 1,7001,800 m, Sohns 1094 (MEXU, P); 10 km al S de Cárdenas, 1000 m, Rzedwosky 5174 (US); 30 miles south of San Luis Potosí, 1890 m, 12 Ago 1958, Reeder \& Reeder 2967 (MEXU). TAMAULIPAS: Hacienda Buena Vista, 18 Jun 1919, Wooton s.n. (US-1061809); vicinity of San Miguel, Bartlett 10591 (GH); K 678 on the Mexico City-Nuevo Laredo highway, $22 \mathrm{~km}$ south of Victoria, Martínez \& Luyando F-2275 (US); low field by corn field, $4 \mathrm{mi} \mathrm{S}$ of Jaumave, Stanford et al. 2338 (US); vicinity of Victoria, 320 m, Palmer 554
(US); Cerro de la Tamulipeca, vicinity of San Miguel, Bartlett 10549 (US); $35 \mathrm{~km}$ from Victoria on the road to Casas And Soto La Marina, ca. 280 m, 3 Oct 1956, Martínez Martínez \& Borja Luyando F-2303 (MEXU, US); $19 \mathrm{~km}$ from Mante on the Tampico highway, 18 Sep 1956, Martínez \& Luyando F-1709 (US). SIN ESTADO: sin localidad, Virlet 1371 (US) (figura 10).

9b. Panicum hallii Vasey var. filipes (Scribn.) F.R. Waller, Southw. Naturalist 19: 105. 1974. Panicum filipes Scribn., Bot. Explor. S. Texas 1: 13. 1895. Tipo: Estados Unidos, Texas, upper part of the "Arroyo" at Corpus Christi, $30 \mathrm{ft}$, 31 Mayo 1894, Heller 1809 (holotipo: US-2463136!; isotipos: NY!, US-953192!, fragmento y foto).

Material examinado: MÉXICO. COAHUILA: $24 \mathrm{~km}$ E of Don Martín Dam, 335 m, 20 May 1939, Harvey 950 (US); El Berrendo, near Múzquiz, Harvey 1186* (MO, US). NUEVO LEÓN: 12 mi. S of China on the road Foward Méndez, 7 Dic 1960, Crutchfield \& Johnston 6068 (US) ; Pan-American Highway from Laredo to Monterrey, near Mamulique Pass, $1500 \mathrm{ft}$, Leavenworth \& Leavenworth 742 (F, MO). SAN LUIS POTOSÍ: El Banito, Chase 7558* (GH). TAMAULIPAS: El Canelo Ranch, 24 mi N of San Fernando on the Matamoros highway, 7 Dic 1959, Johnston 4870 (MEXU); Chamal, Swallen 1716 (US); Hacienda Buena Vista, Wooton s.n. (US 1061807); Laredo, 28.8.1971, Beetle et al. 1031 (MO) (figura 11).

10. Panicum hirsutum Sw., Fl. Ind. Occ. 1: 173. 1797. Tipo: Jamaica, Swartz s.n. (holotipo: S!; isotipo: US-76922!, fragmento y foto ex $\mathrm{S}$ ).

Plantas perennes, robustas, cortamente rizomatosas, con culmos de 1-4 m o más de largo, erectos o postrados con

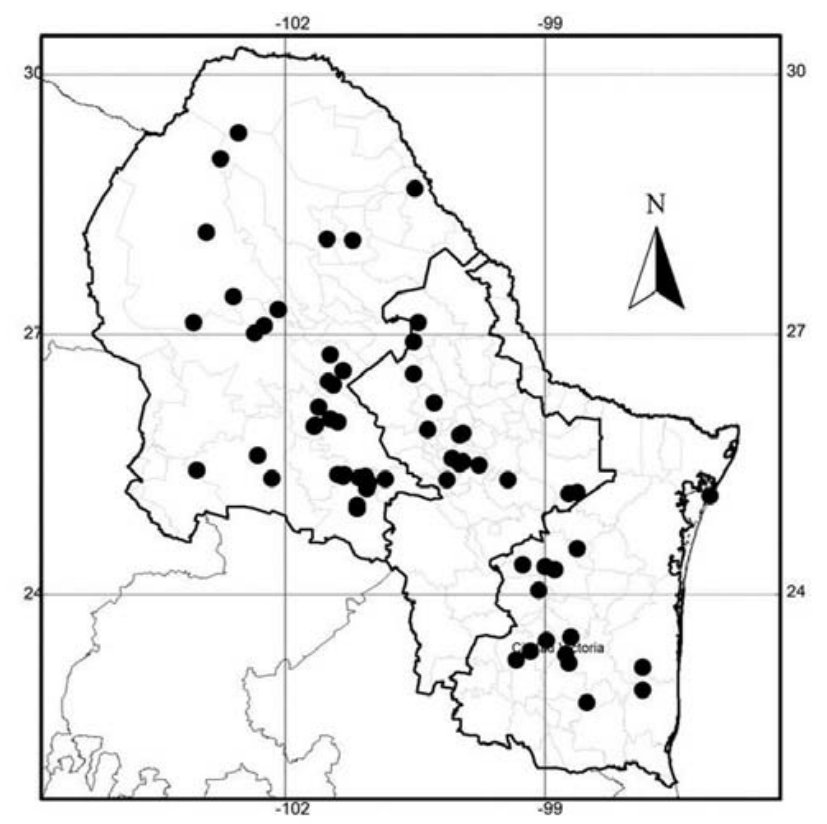

Figura 10. Distribución de • Panicum hallii var. hallii en el Noreste de México. 


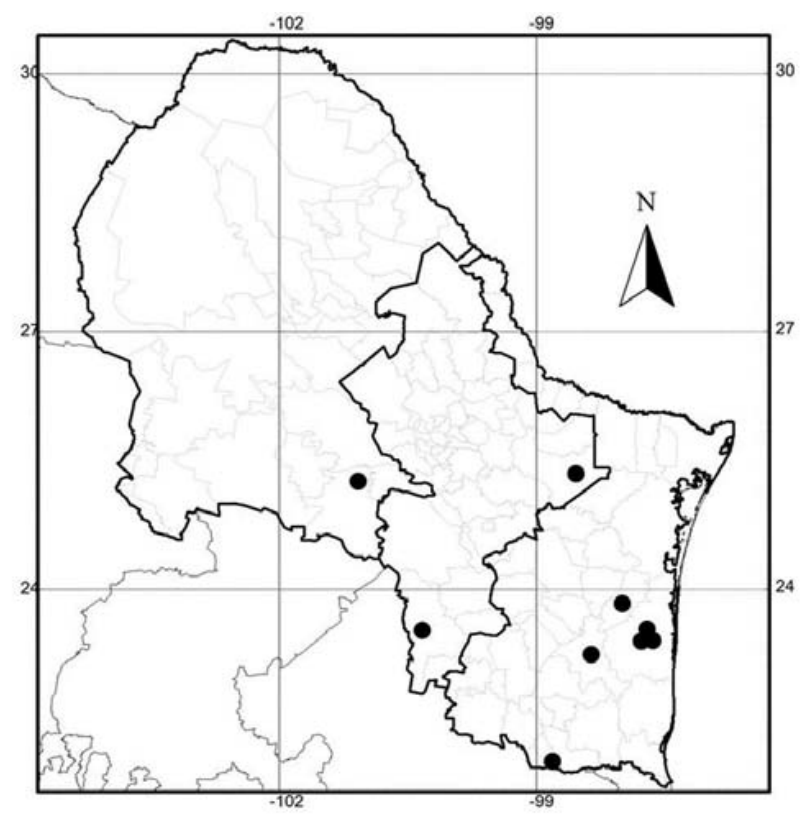

Figura 11. Distribución de • Panicum hallii var filipes en el Noreste de México.

raíces fúlcreas en los nudos inferiores, simples o ramificados en los nudos medios e inferiores; entrenudos de 10-20 $\mathrm{cm}$ de largo, huecos, cilíndricos, pajizos, con pelos tuberculados, urticantes y caducos; nudos contraidos, violáceos, adpreso-pubescentes; vainas de 14-20 cm de largo, más largas o más cortas que los entrenudos, hirsuto-papilosas con pelos urticantes, caedizos, con frecuencia densamente hirsutas en la parte superior, los márgenes membranáceos, con o sin largos pelos; lígulas membranáceas en la base y cortamente ciliadas en la porción superior, de 0.2-0.7 mm de largo; seudolígula presente, pilosa; collar híspido-pubescente; láminas lanceoladas, de 20-70 cm de largo por 10-40 $\mathrm{mm}$ de ancho, planas o involutas, generalmente glabras, a veces esparcidamente papiloso-híspidas, de base subcordada a cordada, los bordes escabriúsculos. Panículas terminales de $20-50 \mathrm{~cm}$ de largo, multifloras, cortamente exertas o incluídas, pedúnculos cilíndricos, hasta de $27 \mathrm{~cm}$ de largo; pulvínulos esparcidamente pilosos a glabros; eje principal anguloso, escabroso; ramificaciones primarias de (11-) 20$35 \mathrm{~cm}$ de largo, las inferiores verticiladas, las restantes opuestas o alternas, adpresas a divaricadas, ejes de las ramificaciones escabrosos; pedicelos en pares de 0.5-2 $\mathrm{mm}$ de largo, escabrosos; espiguillas angostamente ovoides, de 1.7-2.5 $\mathrm{mm}$ de largo por 0.5-1 $\mathrm{mm}$ de ancho, glabras, pajizas, gluma superior y lema inferior subiguales, tan largas como el flósculo superior; gluma inferior de 0.7-1.4 mm de largo, ovada, casi 1/2 del largo de la espiguilla, 3-5-nervia, aguda; gluma superior de 1.7-2.2 mm de largo, 7-11-nervia; lema inferior glumiforme, 7-9-nervia; pálea inferior lanceolada, de 1.2$1.7 \mathrm{~mm}$ de largo, 0.3-0.4 mm de ancho, casi 3/4 del largo de la lema inferior, hialina, con las quillas denticuladas, flor inferior ausente; flósculo superior angostamente elipsoide, de 1.2-1.6 mm de largo por 0.5-0.7 mm de ancho, glabro, liso, brillante, pajizo, castaño a la madurez y con 2 cicatrices en la base de la lema, tempranamente caedizo; pálea con papilas simples hacia el ápice; estambres 3 , anteras de 0.7-0.9 (-1) mm de largo, púrpuras; cariopsis elipsoide, de $0.8-1 \mathrm{~mm}$ de largo por $0.5 \mathrm{~mm}$ de ancho, blanca o pajiza; hilo punctiforme, embrión menos de la mitad del largo de la cariopsis. $\mathrm{n}=18$.

Ecología, distribución y usos: Se encuentra en lugares húmedos, alrededor de estanques, charcos y a lo largo de arroyos y ríos, desde el nivel del mar hasta los $1800 \mathrm{~m}$. Florece desde febrero a diciembre. Distribuída desde el sur de Estados Unidos hasta Sudamérica y el Caribe.

Nombre común: "cortadera", "gamelote", "panicum peludo"

Material examinado: MÉXICO. CAMPECHE: Tuxpeña, 18 Feb 1932, Lundell 1355 (F, GH, MO, NY, US); a 6 km al S de Xpujil, 22 Abr 1982, Cabrera \& Cabrera 2461 (MO, SI); $70 \mathrm{~km}$ al E de Escárcega, 26 Mar 1982, Cabrera \& Cabrera 2237 (MEXU, MO). CHIAPAS: entrance to Cascade Mizola, $25 \mathrm{~km} \mathrm{~S}$ of Palenque, 9159'W, 17²3’N, 280 m, 22 Sep 1988, Stevens \& Martínez 25813 (MO); El Azufre, 700 m, 20 Jun 1983, Méndez 6220 (MO); slopes and small streams with Tropical Rain Forest along the ridges 6-12 km south of Palenque on the road to Ocosingo, $300 \mathrm{~m}, 12$ Oct 1972, Breedlove 28837 (MEXU, MO); Mun. Ocosingo, 8 km NW of Bonampak, Lacanja-Changayab at the Río Lacanja, $350 \mathrm{~m}$, 14 Mayo 1982, Davidse et al. 20528 (MEXU, MO); tropical rain forest adjacent to small cascading river at Agua Azul, $300 \mathrm{~m}, 9$ Nov 1981, Breedlove \& Davidse 55245 (MO). COLIMA: Manzanillo, sea level, Hitchcock 7031 (RB, US). OAXACA: San Antonio, 2 Sep 1894, Pringle 5573* (F, GH, MEXU, MO, US); District of Tuxtepec, Chiltepec and vicinity, 200 m, Martínez Calderón 568 (US); Río Verde, 7 km en línea recta al NE de Santa María Chimalapa, 165' N, 94³9'W, 400 m, Vera Caletti et al. 97 (MO). QUINTANA ROO: 4 km NW of J.M.Morelos, along Hwy. 184, at the place where it crosses the marshes of Laguna Chichancanab, 18 May 1982, Davidse et al. 20612 (MEXU, MO); San José de la Montaña, $9 \mathrm{~km} \mathrm{~S}$ of Hwy. 186 on Hwy. to Tomás Garrido, 120 m, 9 Mayo 1982, Davidse et al. 20271 (MEXU, MO); $3 \mathrm{~km}$ N of San Jose de la Montana, on road N to Thomas Garrido, W of Chetumal, 100 m, 9 May 1982, Davidse et al. 20246 (MEXU, MO); Coba, at edge of lake, Lundell \& Lundell 7622 (US); a $6 \mathrm{~km}$ de la carretera Chetumal-Escarcega, sobre brecha al Ingenio Alvaro Obregón, 5 Jul 1980, Tellez \& Cabrera 2630 (MEXU); a 16 km al Sur de San Jose, rumbo a T. Garrido, 5 Sep 1980, Tellez y Rico 3414 (MEXU). SAN LUIS POTOSÍ: bank of Río Valles, 27 Jun 1910, Leavenworth 199 (GH, MO). TABASCO: Boca Cerro, Tenosique, 1 Jul 1939, Matuda 3577** (F, GH, US); $1.5 \mathrm{~km} \mathrm{~S}$ of Villahermosa, Gilly et al. 243 (GH); km 21 de la carretera Cárdenas-Coatzacoalcos, 17 Sep 1981, Magaña 427 (MEXU, MO). TAMAULIPAS: Altamira, al este de la cabecera municipal, P. Moya 129 (MEXU). VERACRUZ: $9 \mathrm{~km}$ ESE of Ebano on hwy. 70, Nee \& Hansen 18347 (F, MEXU); Estación Biológica San Andrés Tuxtla, 27 Nov 1978, 150 m, Martínez Calderón 1798 (F, MEXU, MO); Finca Sayula, Mun. Paso de Ovejas, Hernández Xolocotzi 3379 (US); near 
the Rio Cozalapa, about 10 miles from El Palmar Rubber Experiment Station, 100 m, 1 Aug 1953, Reeder \& Reeder 1962 (MEXU). YUCATÁN: Becanche, 19 Ene 1956, Enriquez 347 (MEXU). Sin localidad, Gouin 6 (P) (figura 12).

11. Panicum hirticaule J. Presl, Reliq. Haenk. 1: 308.1830. P. polygamun Sw. var. hirticaule (J. Presl) E. Fourn. Mexic. Pl. 2: 28.1886. P. capillare L. var. hirticaule (J. Presl) Gould, Madroño 10: 94. 1949. Tipo: México, Guerrero, Acapulco, Haenke s.n. (holotipo: PR, no visto, fragmento, US-80698; isotipos: MO-1837663!, US-80698!, fragmento). Panicum capillare L. var miliaceum Vasey, Contr. U.S. Natl. Herb. 1: 28. 1890, non P. miliaceum L., 1753. P. sonorum Beal, Grasses N. Amer. 2: 130. 1896. P. hirticaule J. Presl var. miliaceum (Vasey) Beetle, Phytologia 47: 381. 1981. Tipo: México, Sonora, Lerdo, 1889, Palmer 947 (holotipo: US2903025!)

Plantas anuales, con culmos de (15-) 20-130 (-150) $\mathrm{cm}$ de largo por 1-2.5 mm de ancho, erectos o geniculados, decumbentes, simples o ramificados en los nudos medio e inferiores; entrenudos de 4-20 cm de largo, huecos, comprimidos, glabros a papiloso-hirsutos; nudos generalmente hirsutos; vainas de 3-9 cm de largo, más cortas que los entrenudos, papiloso- hirsutas, con un margen pestañoso, el resto glabro; lígulas membranáceo-ciliadas, de (0.5-) 0.8-2 mm de largo; collar glabro o hirsuto; láminas lanceoladas a linearlanceoladas, de 4-25 (-40) cm de largo por (0.2-) 0.4-1.6 $(-2.5) \mathrm{cm}$ de ancho, planas, papiloso-hirsutas a casi glabras, los márgenes basales con pelos papilosos en los márgenes, de base subcordada, el ápice agudo. Panículas terminales y axilares de 5-26 (-35) cm de largo, 5-20 cm de ancho, laxas,

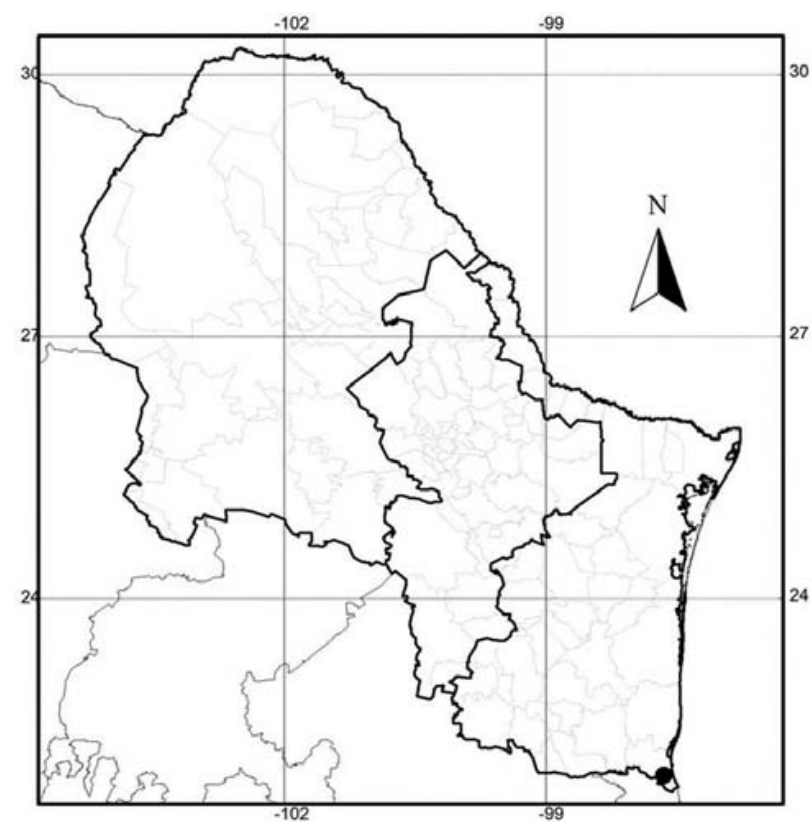

Figura 12. Distribución de • Panicum hirsutum en el Noreste de México. difusas, subincluídas a exertas, con pedúnculos híspidos a glabros, hasta de $35 \mathrm{~cm}$ de largo, multifloras; eje principal anguloso, escabroso, glabro a esparcidamente piloso hacia la base, pulvínulos poco evidentes, glabros; ramificaciones de primer orden de 3-19 cm de largo, alternas, subopuestas o verticiladas, ascendentes a reflexas, ejes de las ramificaciones glabros o pilosos, escabrosos; pedicelos de 1-3 mm de largo, en pares o solitarios, escabriúsculos; espiguillas ovoides de 1.9-3.5 $\mathrm{mm}$ de largo por 0.8-1.3 $\mathrm{mm}$ de ancho, glabras, acuminadas, a veces con un característico color cobrizo o rojizo, gluma superior y lema inferior subyúgales, superando hasta $0.7 \mathrm{~mm}$ en largo al flósculo superior; gluma inferior de 1.3-2.4 mm de largo, 1/2 a 3/5 del largo de la espiguilla, 3-5 nervia, aguda a acuminada; gluma superior de 1.8-3.5 mm de largo, 7-9 (-11)-nervia; lema inferior glumiforme (7-) 9 (-11)-nervia; pálea inferior ausente o de 0.3-0.9 $\mathrm{mm}$ de largo, 1/4 del tamaño de la lema inferior, lanceolada a ovada, glabra en las quillas, ápice entero, truncado o bilocado; flor inferior ausente; flósculo superior elipsoide, de 1.5-2.3 mm de largo por 0.7-0.9 mm de ancho, glabro, con papilas simples en toda la superficie, brillante $\mathrm{u}$ opaco, con dos cicatrices ca. $0.2 \mathrm{~mm}$ de largo en la base, agudo a subagudo; estambres 3, anteras de 0.9-1.3 mm de largo, de color ámbar, naranja o pardo-rojizo; cariopsis elipsoide, de 1-1.7 mm de largo por 0.7-0.8 $\mathrm{mm}$ de ancho, blanquecina; hilo punctiforme, embrión la mitad del largo de la cariopsis. $\mathrm{n}=9$.

Ecología, distribución y usos: Habita en selvas bajas y medianas caducifolias, pastizales, campos de cultivo y en cañaverales, común en áreas húmedas, a orillas de corrientes de agua y caminos, llegando hasta $\operatorname{los} 2500 \mathrm{~m}$. Florece de julio a octubre. Distribuída desde el sur de Estados Unidos hasta Sudamérica y las Antillas. Además de poseer un valor forrajero, de sus granos se obtiene harina para hacer pan.

Nombres comunes: "triguillo”, "panizo cauchín”, "panizo aserrín triguillo", "zacate del año", "zacate peludo perdis", "panizo güarijío" y "zacate capiro".

Material examinado: MÉXICO. BAJA CALIFORNIA SUR: km 65 east of San Antonio, 6 Jun 1973, Beetle M-2551 (MO); 5 miles east of San Antonio, 8 Ene 1973, Beetle M-2646 (MO); Mesa de San Gerónimo, northely from Rancho Viejo (on road from Loreto to San Javier), 23 Sep 1965, Carter 5016 (LA, MEXU). CHIAPAS: marshes along Rio Usumacinta, 25-30 km east northeast of Palenque Junction, 30 m, 12 Dic 1981, Breedlove 56081 (MO, NY); along road from Highway 195 to Simojovel de Allende, $2.7 \mathrm{mi}$ past village of El Bosque at km 21.5, $1030 \mathrm{~m}, 16 \mathrm{Feb}$ 1979, Croat 47699 (MO); forest at Mirador for Chicoasen Dam along road from Tuxtla Gutiérrez to the Chicoasen Dam, 850 m, 17 Nov 1976, Breedlove 41540 (MO). COAHUILA: Municipio de Ocampo, Laguna de La Leche, Valdés-Reyna Jesús 1335 y L.E. Rodríguez G. (ANSM); Municipio de Viesca, Camino al Bajío de Ahuichila 16 Km S de Viesca, Villarreal-Quintanilla José Angel 7730 y M.A. Carranza P. (ANSM); CHIHUAHUA: N end of E side of Sierra 
del Cuchillo Parado, 29³7'N, 104º5' 'W, 1000-1300 m, 21 Oct 1972, Wendt et al. 9788 (MO, NY); $20 \mathrm{Km} \mathrm{S}$ of Ciudad Camargo, 1220 m, 1 Jul 1939, Harvey 1378 (GH, MO, US); Hacienda San Miguel, Palmer 1c (GH, NY); Nabogame, 28³0’N, 108³0’W, 1800 m, 10 Nov 1988, Laferriere 2725 (MO); Guasaremos, Río Mayo, 20 Sep 1935, Gentry 1841 (MEXU, MO, US); Sierra Madre Occidental, W of Casas Grandes, 5 miles of Hernández, 700 ft, 18 Sep 1960, Reeder et al. 3517 (US); 6 miles west of Piloncillo, 24 Sep 1938, Johnston 7866 (GH). CHIHUAHUA-SONORA: Rancho Carreteras, 1460 m, 26 Ago 1939, Harvey 1600 (MO, US). COLIMA: Alzada, 21 Sep 1910, Hitchcock 7089* (US); along hwy. 110, site 52, 25 Jul 1975, Wallace et al. 292 (MEXU, MO); Colima, Jul 1897, Palmer 143 (ISC, NY, US, W). DURANGO: 10 $\mathrm{km} \mathrm{N}$ of Ceballos and $81 / 2 \mathrm{~S}$ of Chihuahua state line on the TorreonChihuahua highway, $1200 \mathrm{~m}, 26^{\circ} 36^{\prime} \mathrm{N}, 102^{\circ} 12^{\prime} \mathrm{W}$, Johnston et al. 12292 (MEXU, MO). GUERRERO: south Chilpacingo, 7 Dic 1941, Leavenworth 966 (MO); Río Balsas, 26 Ago 1910, Orcutt 4197 (MO); Balsas, 1500 ft, 9 Sep 1910, Hitchcock 6814 (US). GUANAJUATO: Irapuato, 5800 ft, 1 Oct 1910, Hitchcock 7424 (US). JALISCO: $34 \mathrm{~km}$ west of La Barca, 27 Ago 1981, Beetle M-7030 (MO); ca. 5 road-miles SW of Santa Cruz de las Flores, 1550 m, 24 Ago 1957, McVaugh 16326 (MEXU, NY, US); Tecalitlán, al S de Tecalitlán, rumbo a Pihuamo, 12 Ago 1987, Ornelas U. et al 1167 (MEXU). MÉXICO: Temascaltepec, Anonas, 24 Jul 1934, Hinton 6337 (MO, NY, US); Temascaltepec, Barranca, Ixtapán, 1000 m, Hinton 1062 (F, MEXU, NY, US). MICHOACAN: Chavinda, 27 Sep 1946. Hernández Xolocotzi et al. $x$-2775 (US); Huétamo, 1938, 240 m, Gándara 2 (US); at edge of tropical deciduous forest, La Majada, 8 May 1941, Leavenworth \& Hoogstrall 1335 (GH, NY). NAYARIT: 1 mile west of Mazatán, 600 m, 17 Sep 1960, McVaugh 19117 (NY, US); near km 31, 4-5 miles N of Compostela, 22 Sep 1960, McVaugh 19333 (NY, US). OAXACA: Tomellin, 14 Ago 1910, Hitchcock s.n., Amer. Gr. Herb. 28 (GH, NY); 2 km al SE de San Martín Toxpalán, por carretera a Teotitlán del Camino, 26 Ago 1980, Medrano et al. F-1495 (MO); Los Tules Niltepec, 11 Dic 1985, Torres C. et al. 7860 (MEXU, MO). SONORA: AlamoMexican boundary linnear White Water, 11 Sep 1893, Mearns 2294 (US); El Rancho de la Nacha, $25 \mathrm{mi}$. W of La Angostura, 4300 ft, 14/20 Ago 1941, Vera Santos 1842 (GH, LA), 1850 (GH, LA, MEXU, MO, NY); 5 mi. E of El Rancho de la Nacha, 16 Ago 1941, Vera Santos 1836 (GH, US); 10 mi. S of Nogales, 16 Sep 1908, Hitchcock 3631 (US); summit of Cerro Prieto in the vicinity of the microwave station, $15 \mathrm{~km}$ E of Navojoa above the road to Alamos, 5 Sep 1989, Sanders et al. 9297 (MO); 27 miles west of Hermosillo on the road to Kino Bay, $720 \mathrm{ft}, 28$ Ago 1941, Wiggins \& Rollins 137 (GH, LA, MO, NY); Cañón de Huépari, north of Aribadi, 1310 m, 2 Sep 1939, Harvey 1653 (GH, MO); S of Hermosillo, 17/20 Sep 1908, Hitchcock 3604 (US). TABASCO: km 6.6 de Emiliano Zapata hacia Tenosique, 5 Jul 1981, Cowan 3398 (MEXU, MO). TAMAULIPAS: Municipio de Aldama, Rumbo al Ejido Santa Juana, Sandoval-Hernández Raymundo 59 (MEXU); Municipio de Gomez Farías, Camino a la cancha de Fut-bol, Crespo-Ovalle María Eliza 443 (ANSM); Ejido El Azteca, Camino de Gómez Farías, Crespo-Ovalle María Eliza 249 (ANSM); Ejido Sabinas, Crespo-Ovalle María Eliza 414 (ANSM); Entrada al Ejido El Nacimiento, Crespo-Ovalle María Eliza 301 (ANSM); Gómez Farías, Crespo-Ovalle María Eliza 96 (ANSM); Municipio de González, $7 \mathrm{Km}$ al NO de González, Galván-Infante J. Guadalupe 312 (MEXU); Municipio de Miquihuana, Ejido Valle Hermoso, Galván-Infante J. Guadalupe 32 (MEXU); San José de las Rusias, Municipio de Soto la Marina, Ejido 5 de Mayo, FrancoLópez Juan Antonio 75 (MEXU); Municipio de Xicoténcatl, Xicotencatl, López-Aguilar Carmen Rafael 58 (MEXU). VERACRUZ: La Mancha, carretera Cardel-Nautla, 1 Ago 1971, Dorantes 246bis (F, GH); Baños del Carrizal, Purpus 6212 (GH, LA, MO, NY). YUCATÁN: Chichankarrab, Gaumer 1501 (F) (figura 13).

12. Panicum lepidulum Hitchc. \& Chase, Contr. U.S. Natl. Herb. 15:75, f. 64. 1910. Tipo: México, Chihuahua, rocky hills near Chihuahua, 22 Sep 1885, Pringle 497 (holotipo: US-155163!; isotipos: F!, MEXU!, NY!, US-742174!, W!). Plantas perennes, cespitosas y cortamente rizomatosas, con culmos de (0.15-) $0.25-1 \mathrm{~m}$ de largo por 1 a $2 \mathrm{~mm}$ de diámetro, erectos o ligeramente geniculados en los nudos inferiores, simples o escasamente ramificados en los nudos inferiores; entrenudos de 4-18 cm de largo, cilíndricos, glabros o papiloso-hirsutos; nudos pilosos; vainas más largas o más cortas que los entrenudos, papiloso-hirsutas,con pelos tuberculados caedizos, los márgenes ciliados; lígulas membranáceo-ciliadas, de (0.6-) 2 (-3) mm de largo; collar glabro o piloso; láminas linear-lanceoladas, de 7-26 (-30) $\mathrm{cm}$ de largo por $0.4-1.2 \mathrm{~cm}$ de ancho, ascendentes, planas o con los márgenes enrollados, papiloso-hirsutas a ocasionalmente glabras, de base redondeada y ápice acuminado, los márgenes basales ciliados. Panículas terminales exertas de 7-20 (-30) cm de largo, 4-9 cm de ancho, laxas, multifloras, pedúnculos glabros a hirsutos, hasta de $30 \mathrm{~cm}$ de largo; eje principal hirsuto hacia la porción basal o glabro, pulvínulos glabros; ramificaciones de primer orden de $1.5-5.7 \mathrm{~cm}$ de largo, alternas, ascendentes; ramificaciones de segundo orden cortas, llevando pocas espiguillas solitarias; pedice-

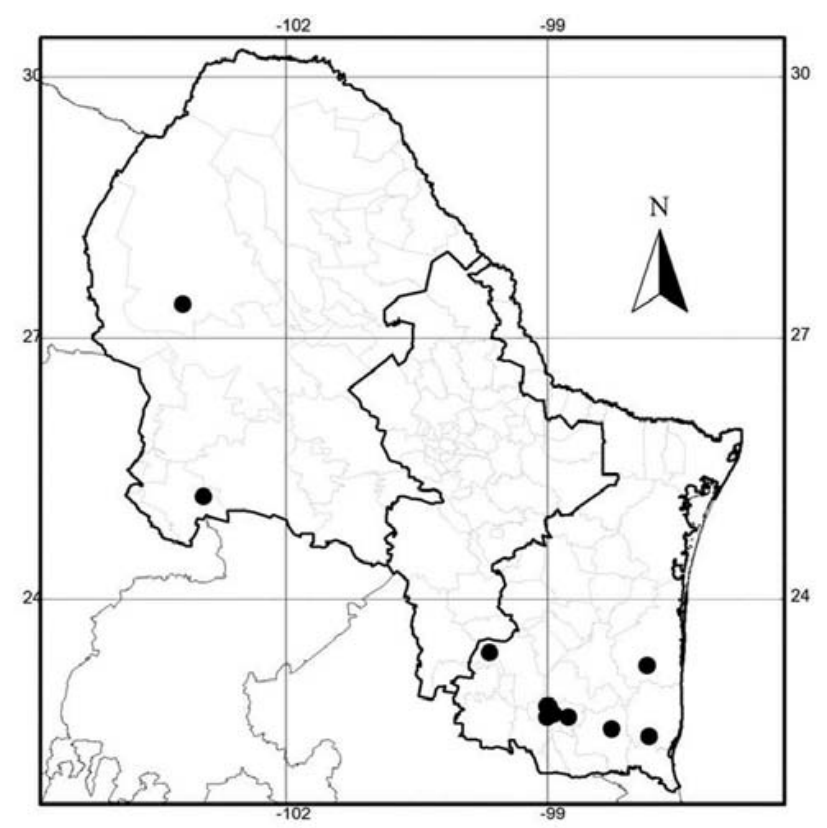

Figura 13. Distribución de $•$ Panicum hirticaule en el Noreste de México. 
los de 2-12 mm de largo; espiguillas largamente ovoides, de (3.3-) 3.6-4.2 $\mathrm{mm}$ de largo por 1-1.5 $\mathrm{mm}$ de ancho, glabras, acuminadas, no estipitadas, gluma superior y lema inferior subyúgales, 0.9-1.5 mm más largas que el flósculo superior; gluma inferior de 1.6-2 mm de largo, la mitad del largo de la espiguilla, 5-nervia; gluma superior de 3.3-3.6 mm de largo, 9-15-nervia; lema inferior glumiforme, ligeramente más larga que la segunda gluma, (7-) 9-nervia; pálea inferior ovado-lanceolada, de 1.2-2 mm de largo, 1/4 a 1/3 del tamaño de la lema inferior, hialina, glabra, diminutamente bilobada, flor inferior ausente; flósculo superior ovoide de 2- $2.5 \mathrm{~mm}$ de largo por 1-1.5 mm de ancho, crustáceo, glabro, liso, con un anillo circular en la base, agudo, castaño a la madurez; lema 7-nervia, pálea con papilas simples y micropelos globosos hacia el ápice; estambres 3, anteras de $1 \mathrm{~mm}$ de largo, púrpuras; cariopsis ovoide, de $1.8 \mathrm{~mm}$ de largo por $1 \mathrm{~mm}$ de ancho; hilo oblongo, embrión la mitad del largo de la cariopsis.

Ecología, distribución y usos: Crece en lugares montañosos y húmedos de selva baja caducifolia, en áreas abiertas de bosque de pino-encino o encino, cañadas, pastizales y a orillas de caminos, desde el nivel del mar hasta los 2400 m. En floración de marzo a noviembre. Distribuída desde México hasta Guatemala. Su valor forrajero es bueno.

\section{Nombre común: "panizo lepidio".}

Material examinado: MÉXICO. AGUASCALIENTES: 8 mi. E of Calvillo, 6900 ft, 25 Sep 1963, Reeder \& Reeder 3814 (MEXU, US); Pabellón, San Carlos, 29 Oct 1978, Guardado s.n. (MEXU-272159); Cerro del Picacho, 16 Nov 1978, González s.n. (MEXU-272160). CHIAPAS: Arriaga, savanna $2 \mathrm{~km}$ SE of Arriaga, Breedlove 36852 (NY). CHIHUAHUA: $12.8 \mathrm{mi}$. W of General Trias on Rte. 16, ca. 1780, 21 Ago 1979, Wagner \& Solomon 4341* (MO). COAHUILA: Sierra de la Madera, vicinity of La Cueva, Johnston 9104* (GH, MEXU). DISTRITO FEDERAL: Near Mexico City, Pedregal, Hitchcock 5958 (F, GH, NY, US); San Angel, 16 Ago 1929, Mexía 2740 (MO); Pedregal de San Angel, $1 \mathrm{~km}$ to the south of UNAM, 8 Jul 1967, Nee 183 (MEXU). DURANGO: Durango, Hitchcock 7591 (NY, US), Palmer 525 (F, GH, MEXU, MO, NY, RB, US); Tobar, Palmer 533 (US); 46 miles NE of Durango on the Durango-Torreón road, 6300 ft, 30 Sep 1959, Soderstrom 812 (MEXU, US); 21 mi. SE of Durango, $5800 \mathrm{ft}, 19$ Oct 1966, Gould 12322 (US). GUANAJUATO: 2-4 km east of Guanajuato, Sohns 288 (US); about $3 \mathrm{~km} \mathrm{NE}$ of San Miguel, occasional in rocky soil near the top of Cerro de La Presa, Sohns 504 (US); Ojo de Agua, a small hill about one mile south of Abasolo, Sohns 253 (US); 2-4 kms east of Guanajuato, Sohns 285 (US); Santa Cruz de Juventino Rosas rumbo a Guanajuato, 2 Sep 1981, Beetle M-7324 (MO). HIDALGO: steep rocky volcanic outcrops at head of descent into Barranca de Metztitlán between Zoquital and Los Venados, 2000 m, Moore Jr. 4218 (GH, US); Jacala, 24 Jun 1939, Chase 7089 (US). JALISCO: Paso de la Troje, near km 36, southwest of Ojuelos on road to Aguascalientes; rocky slopes on and near Cerro La Campana, McVaugh 16819 (NY, US); on rocky pastured slopes, 11 miles north of Ciudad Guzmán, Gould 9643 (US); Zapotlán,
5000 ft, Hitchcock 7117, 7238 (US); San Nicolás, 5000-6000ft, Hitchcock 7199 (US); mountains north of Autlán, 3-5 miles above Mina San Francisco, 1600-1800 m, McVaugh 19651, 19578 (US); about 7 miles south of lagos de Moreno, 2040 m, 13 Sep 1953, Reeder \& Reeder 2300 (MEXU, US); ca. $7 \mathrm{mi} \mathrm{SE}$ of the junction of Hwy 80 and 45 at Lagos de Moreno, 1800 m, 21 Ago 1975, Davidse \& Davidse 9927* (MEXU, MO). MÉXICO: $3 \mathrm{~km}$ al W de San Cristóbal Ecatepec, base de la Sierra de Guadalupe, 2400 m, 18 Ago 1974, Rzedowski 32145 (MEXU). MICHOACÁN: 1.7 mile NW of Tuxpan, 1780 m, Davidse 9806 (MO); ca. 16 miles N of the junction of highways 37 and 15, Davidse 9912* (MO); vicinity of Morelia, Arséne 2417* (GH, MEXU, MO, NY, US), 2864 (MO, US), 2985 (GH, MO, US); about 16 km WSW of Morelia, km 329 on Hwy. 15 (Morelia to Quiroga), Cerro del Aguila, 2000 m, 11 Sep 1962, Ugent \& Flores 1893 (SI); SSW of Morelia on the road to Villa Madero, $2000 \mathrm{~m}, 19$ Jul 1963, Ugent \& Flores 5801 (SI); 25 km east of Morelia on Mex 15, 2000 m, 20 Oct 1976, Brunken \& Perino 444 (MEXU); $10 \mathrm{~km}$ al S de Morelia, sobre el camino directo a Atécuaro, 2300 m, 17 Ago 1990, Rzedowski 49933 (ANSM). MORELOS: Barranca de Atzingo, 1900-2000 m, 7 Mar 1972, Vázquez 3592 (MEXU). OAXACA: Hacienda Aguilar, 1580 m, 23 Jul 1919, Conzatti 3603 (MEXU, US); 13.5 mi. SW of Sola de Vega along the road to Puerto Escondido, $1920 \mathrm{~m}$, 14 Ago 1975, Davidse 9657 (MO). PUEBLA: Tehuacán, 5500 ft, Hitchcock 6063 (MEXU, US). QUERÉTARO: Near San Juan del Río, 18 Ago 1905, Rose et al. 9555 (MEXU, NY, US). SAN LUIS POTOSÍ: Las Canoas, 20 Jul 1910, Hitchcock 5756 (US); in and along open border of oak forest, 4 miles east of Ciudad de Maíz, Gould 10796 (US); near the village of San Francisco in the Sierra de San Miguelito about 25 kms. SW of San Luis Potosí, 2200-2400 m, Sohns 1066 (US); 8 km al W de San Lorenzo, km 62 carretera S.L. Potosí-A. Morelos, 1800 m, Rzedowski 565 (US); W de Villa Hidalgo, 1850 m, 22 Ago 1954, Rzedowski 3775 (US); 3 km al W de Tierra Nueva, 7 Sep 1954, Rzedowski 796 (US); between Santa María del Río and Tierra Nueva, in the Sierra de Alvarez, 1700-1800 m, 7 Sep 1954, Sohns 1114 (US). SONORA: Valle de Teras, near La Angostura, White 3542*(GH). ZACATECAS: Zacatecas, Hitchcock 7510 (US); Zacatecas, road to Huejuquilla el Alto, 1 mile west of the road-junction 18 miles south of Valparaíso on the road to Mezquitic, McVaugh 17705 (US); Chapingo, km 846 carretera Juárez, 26 km al N de Fresnillo cerca de Tropico de Cáncer, 2150 m, 12 Sep 1955, Hernández \& Mathus n-1667 (US) (figura 14).

13. Panicum parcum Hitchc. \& Chase, Contr. U.S. Natl. Herb. 15:68, f. 53. 1910. P. decolorans Kunth. var. parcum (Hitchc. \& Chase) Beetle, Phytologia 54: 4. 1983. Tipo: México, Sinaloa, Lodiego on the Culiacán River, 9-15 Oct 1981, Palmer 1657 (holotipo: US-471378!; isotipos: F!, ISC!, NY!, P!).

Plantas anuales, cespitosas, con culmos de 0.2 a 0.9 (-1.25) $\mathrm{m}$ de largo por 1 a $2(-3) \mathrm{mm}$ de ancho, erectos o geniculados; entrenudos de 5-20 cm de largo, huecos, glabros o papiloso-hirsutos; nudos glabros, castaños; vainas de 10-13 $\mathrm{cm}$ de largo, generalmente más cortas que los entrenudos, papiloso-híspidas, los márgenes ciliados; lígulas membranáceo-ciliadas, de 1-1.3 mm de largo, la porción membranácea corta; collar hirsuto, castaño; láminas linear-lanceoladas, de 6-35 (-45) cm de largo por (2-) 3-10 mm de ancho, planas, 
hirsuto-papilosas con pelos caedizos, los márgenes basales ciliados, el resto escabriúsculos, de base angostada y ápice agudo. Panículas terminales y axilares presentes, de 7-35 $(-40) \mathrm{cm}$ de largo, subincluidas a exertas, laxas y difusas, paucifloras, pedúnculos de 10-35 $\mathrm{cm}$ de largo, hirsutos en la porción distal; eje principal anguloso, escabriúsculo, hirsuto o no hacia la base, pulvínulos violáceos, glabros; ramificaciones de primer orden de (2-) 6-18 cm de largo, alternas, divaricadas, ejes de las ramificaciones escabrosos; pedicelos solitarios de 5-18 $\mathrm{mm}$ de largo, escabriúsculos; espiguillas ovoides de 4.5-6 cm de largo por $1.5-2 \mathrm{~mm}$ de ancho, glabras, verdosas y con tintes violáceos, ascendentes a divaricadas, acuminadas, gluma superior y lema inferior subyúgales, 1.2-1.8 mm más largas que el flósculo superior; gluma inferior de (2.7-) 2.9-4.2 mm de largo, 3/5 a 4/5 del largo de la espiguilla, 5-7-nervia, aguda a acuminada, separada de la gluma superior por un entrenudo ca. $0.6 \mathrm{~mm}$ de largo; gluma superior de 3.8-5.4 mm de largo, 9-11 nervia; lema inferior hasta $0.9 \mathrm{~mm}$ más corta que la gluma superior, 9-11 nervia; pálea inferior lanceolada, de 1.2-2 mm de largo, 1/3 a 1/2 del tamaño de la lema inferior, glabra, el ápice diminutamente eroso o entero; flor inferior ausente; flósculo superior ovoide, de 2.8-3.4 mm de largo por 1.4-2 mm de ancho, endurecido, liso, de base circular, agudo a obtuso; lema 7-nervia, pálea con papilas verrugosas en el ápice; estambres 3, anteras de 1.2-2 mm de largo, de color púrpura o púrpura-rojizo; cariopsis ovoide, de 2.3-2.5 mm de largo por 1.4-1.8 mm de ancho, blanquecina; hilo punctiforme, embrión un medio del largo de la cariopsis. $\mathrm{n}=18$.

Ecología, distribución y usos: Crece en bosques de encinos,

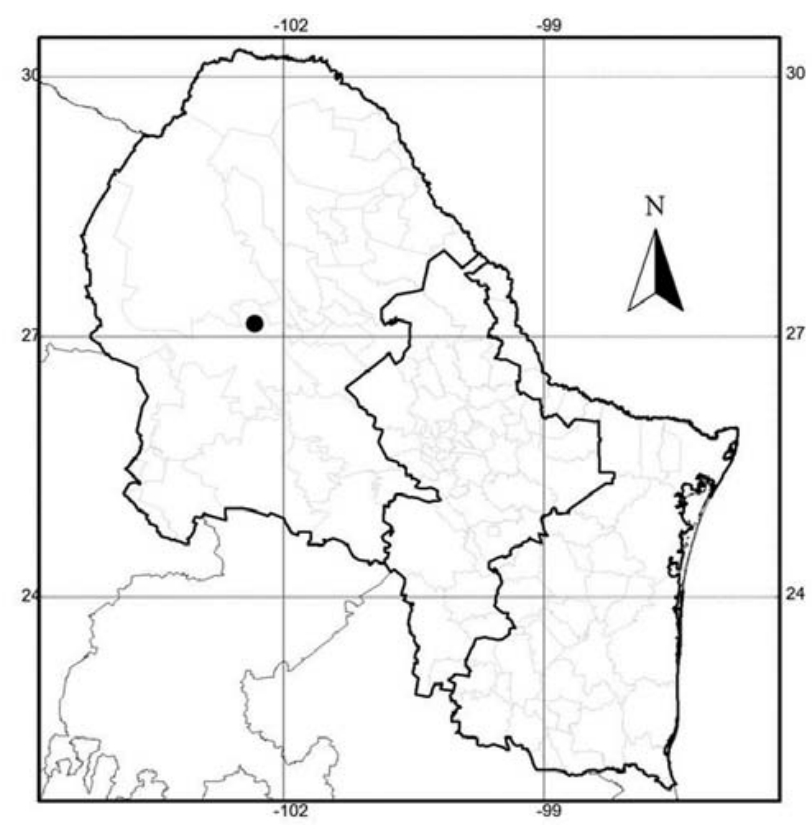

Figura 14. Distribución de • Panicum lepidulum en el Noreste de México. de pino-encino, selvas bajas caducifolias, selvas medianas subcaducifolias y también en áreas abiertas de bosque de pino o pastizales, desde el nivel del mar hasta los $2070 \mathrm{~m}$. En floración de julio a diciembre. Distribuída desde el norte de México hasta Costa Rica.

Material examinado: MÉXICO. CHIAPAS: $9 \mathrm{~km}$ southwest of Cintalapa, Gould 12757 (GH, US); 14 km E of Ocozocuatla,in open grassy field, Gould 12729* (MO, US); near junction at Las Cruces on road to La Ciénaga, 853 m, 18 Sep 1981, Breedlove 52871 (MO); small forested stream and adjacent savanna $2 \mathrm{~km} \mathrm{SE}$ of Arriaga, 100 m, 27 Ago 1974, Breedlove 36875 (MEXU, MO); $9 \mathrm{~km}$ north of Tuxtla Gutierrez, along road to El Sumidero, $2500 \mathrm{ft}$, 27 Oct 1965, Breedlove \& Raven 13492 (F, US), 13833 (F, MEXU, US); $10 \mathrm{~km}$ east of Arriaga on Mexican Highway 200, 31 Oct 1981, Breedlove \& Davidse 54261 (MEXU, MO); western side of Tuxtla Gutierrez, 13 Sep 1965, Gould 11676 (US). CHIHUAHUA: Río Negro, 28.8.1937, Le Sueur 173 (US). COLIMA: Alzada, Hitchcock 7081 (RB, US). COAHUILA: Municipio de Ocampo, Rancho La Rueda, $87 \mathrm{Km}$ NO de Ocampo, Ibarra Daniel s/n (ANSM). DURANGO: $14 \mathrm{mi}$ SE of Durango, about $600 \mathrm{ft}, 16$ Oct 1966, Gould 12288 (US). GUANAJUATO: km 20 N de Silao, 16 Sep 1946, Hernández Xolocotzi et al. X-2468 (US). GUERRERO: Balsas, Hitchcock 6782 (F, MO, NY, US), 6808, 6810, 6811 (US); Coyuca, Santa Barbara, 29 Sep 1934, Hinton 6686 (GH, MO, NY, US); along road from Almoloya-Teloloapan-Iguala, 5900-9000 ft, 10 Oct 1953, Sohns 960 (US); Cañón de La Mano, entre Los Amates y El Naranjo, $10 \mathrm{~km}$ al $\mathrm{N}$ de Iguala por el ferrocarril, 900-1000 m, 12 Sep 1986, Catalán \& Terán 92 (MO). JALISCO: about 13 miles northwest of León, Guanajuato in a grassy area with scattered thorny shrubs, $2070 \mathrm{~m}$, Reeder \& Reeder 2288 (MEXU, US); steep rounded hills ca. 8 miles southwest of La Resolana, road to La Huerta, McVaugh 21107 (US). MICHOACÁN: West-facing slopes of Cerro de Carboneras, ca. $22 \mathrm{~km} \mathrm{~S}$ of Uruapan, 3300-3700 ft, King \& Soderstrom 4831 (MEXU, NY, US); on steep slopes of barrancas on road from Uruapan to Nueva Italia, Sohns 834, 836 (US); along road from Tsitzio-Tiquicheo-Huetamo-Altamirano, Sohns 905, 922, 945 (US). MORELOS: Xochiltepec, 24 Sep 1938, Lyonnet 2639 (MEXU, MO, US). NAYARIT: Nayar, 8 km al NW de San Juan Peyotán, en los límites de Nayarit y Durango, 22³0'N, 104³0'W, 600 m, 21 Sep 1989, Flores F. \& Tenorio L. 1197 (MEXU, MO); Mun. Nayar, 3.9 km al NE de Jesús María, camino a Huejuquilla, $22^{\circ} 16^{\prime} \mathrm{N}, 104^{\circ} 30^{\prime} \mathrm{W}, 530 \mathrm{~m}$, selva baja caducifolia, 15 Sep 1989, Flores et al. 1053 (MEXU, MO); Mun. Nayar, $7 \mathrm{~km}$ al NW de San Juan Peyotan, brecha a Huazamota, 22 26N, 104 29W, 600 m, 21 Sep 1989, Tenorio \& Flores 16264 (MEXU). OAXACA: 11 mi. W of Zanatepec, 150 m, 28 Ago 1953, Reeder \& Reeder 2152 (MEXU, US); 40 miles NE of Juchitan, in moist opening in brush-forest area, Gould 11669 (US); $151 \mathrm{~km}$ SW of Oaxaca, on highway 190, 1100 m, 15 Oct 1976, Brunken \& Perino 368 (MO); 10 miles W of Tehuantepec on Mex 190, 240 m, 14 Oct 1976, Brunken \& Perino 360 (MO); near km post 184 on Hwy. 190, ca. 40 miles NW of Tehuantepec, 710 m, 13 Ago 1975, Davidse 9587 (MO); about 42 miles west of Tehuantepec on grass-covered slopes, 760 m, Reeder \& Reeder 2164 (MEXU, US). PUEBLA: Mesa del Pochote $3 \mathrm{~km}$ al E de El Salado, bosque de Quercus, 1310 m, 20 Oct 1985, Guízar 1850 (ANSM, CHAPA). SINALOA: Cofradía, vicinity of Culiacán, 31 Oct 1904, Brandegee 4 (US); Las Mesas, Sierra Surotato, ca. 3000 ft, 15 Sep 1941, 


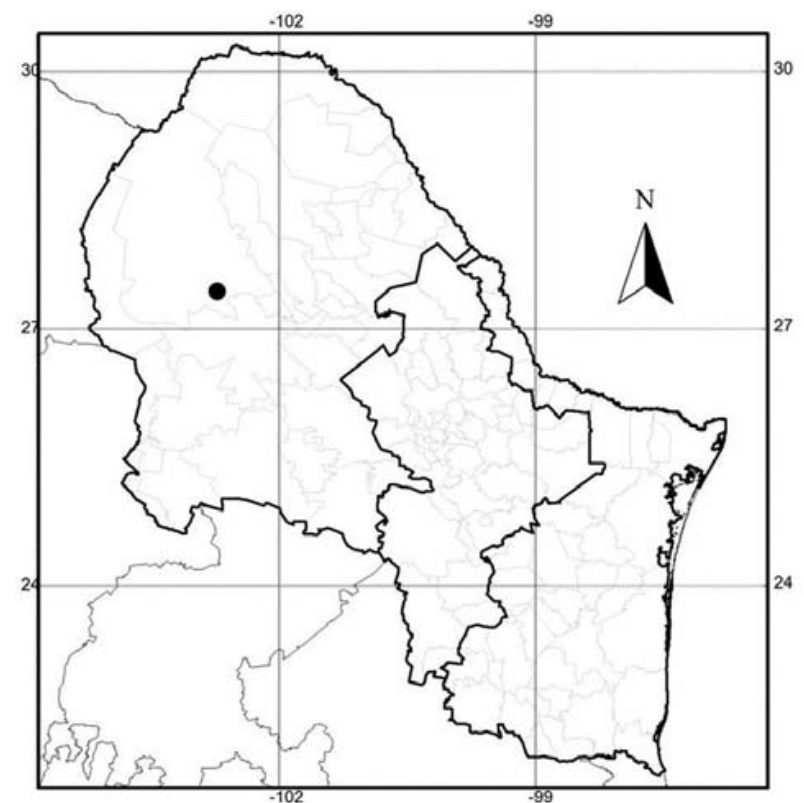

Figura 15. Distribución de - Panicum parcum en el Noreste de México.

Gentry 6667 (GH, MEXU, MO, NY), Harvey 6667 (MO). Temascaltepec, Bejucos, Hinton 1996 (GH, NY), 2000 (NY, US). SIN ESTADO: Alzada, 4 Oct 1910, Orcutt 4687 (US) (figura 15).

14. Panicum rigidulum Bosc ex Nees, Fl. Bras. Enum. Pl. 2: 163. 1829. Tipo: Estados Unidos, sin localidad, Bosc s.n. (holotipo: B-W!). Panicum agrostoides Spreng., Pl. Min. Cogn. Pug. 2:4.1815. Tipo: Estados Unidos, Pennsylvania, H.C. Muhlenberg s.n. (lectotipo: designado por Hitchcock \& Chase, 1910, B-W, no visto; isolectotipo: US-80450!, fragmento ex B-W).

Planta perenne, cespitosa, con culmos de 0.4-1.5 m de largo, huecos, erectos o decumbentes, frecuentemente ramificados en los nudos superiores; entrenudos glabros o rara vez híspidos; nudos glabros o rara vez híspidos; vainas más cortas que los entrenudos, glabras o rara vez híspidas, comprimidas y quilladas; lígulas membranáceas y cortamente laciniadas, de 0.4-1 mm de largo; collar glabro o con una línea de pelos; láminas linear-lanceoladas, de 20-50 cm de largo por 4-12 $\mathrm{mm}$ de ancho, glabras o esparcidamente pilosas, planas o involutas. Panículas terminales y axilares de 10-40 cm de largo, ligeramente contraídas o abiertas; ramificaciones de primer orden de (3-) 6-10 cm de largo, adpresas a ascendentes; generalmente solitarias, escabriúsculas; ejes glabros o los de las ramas y pedicelos con pocos pelos; espiguillas lanceoladas, de 1.6-2.8 mm de largo, glabras, agudas; gluma inferior de 1.5-2.1 mm de largo, 4/5 o ligeramente menor de largo de la espiguilla, 3-nervia, aguda; gluma superior de 1.6-2.8 mm de largo, 3-nervia; lema inferior igual o un poco más corta que la gluma superior, 5-7-nervia; palea inferior casi 3/4 de la lema inferior, hialina, glabra; flor infe- rior ausente; flósculo superior angostamente lanceolado, de 1.2-1.5 mm de largo por 0.5-0.7 $\mathrm{mm}$ de ancho, liso, brillante, glabro, subagudo, con o sin un corto estípite en la base, lema con dos conspicuos aguijones en el ápice; estambres 3, anteras de 0.5 a $0.7 \mathrm{~mm}$ de largo; cariopsis no vista. $\mathrm{n}=9$.

Ecología, distribución y usos: Crece en pantanos, pastizales húmedos, arroyos, bosques abiertos y a lo largo de arroyos y canales, frecuentemente en lugares sombreados. Se distribuye desde Canadá hasta Guatemala y las Antillas.

Nombre común: "panizo punta roja”.

Material examinado: COAHUILA: Marsh 578-A, 928 (TEX-LL) (figura 16).

15. Panicum tamaulipense F. R. Waller \& Morden, Syst. Bot. 8: 221. 1983. Tipo: México, Tamaulipas, between La Chona and Río Santa Olaya, 50 m, 26 Sep 1956, Martínez Martínez \& Borja Luyando F-2161 (holotipo: TEX, no visto; isotipo: US-2463101!).

Plantas perennes, cespitosas, con culmos de (20-) 50-80 $(-120) \mathrm{cm}$ de alto por 1 a $2 \mathrm{~mm}$ de diámetro, erectos, simples; entrenudos cilíndricos, huecos, cortamente hirsuto-pubescentes, ocasionalmente glaucos; nudos con pelos cortos; vainas de 8-12 cm de largo, iguales o más largas que los entrenudos, glabras o hirsuto-papilosas con pelos tuberculados adpresos, un margen pestañoso, el restante glabro; lígulas membranáceo-ciliadas, de 0.5-1.2 mm de largo; collar piloso a glabro; láminas linear-lanceoladas, de (8-) $10-50 \mathrm{~cm}$ de largo por 3 a $8 \mathrm{~mm}$ de ancho, planas o involutas, glabras,

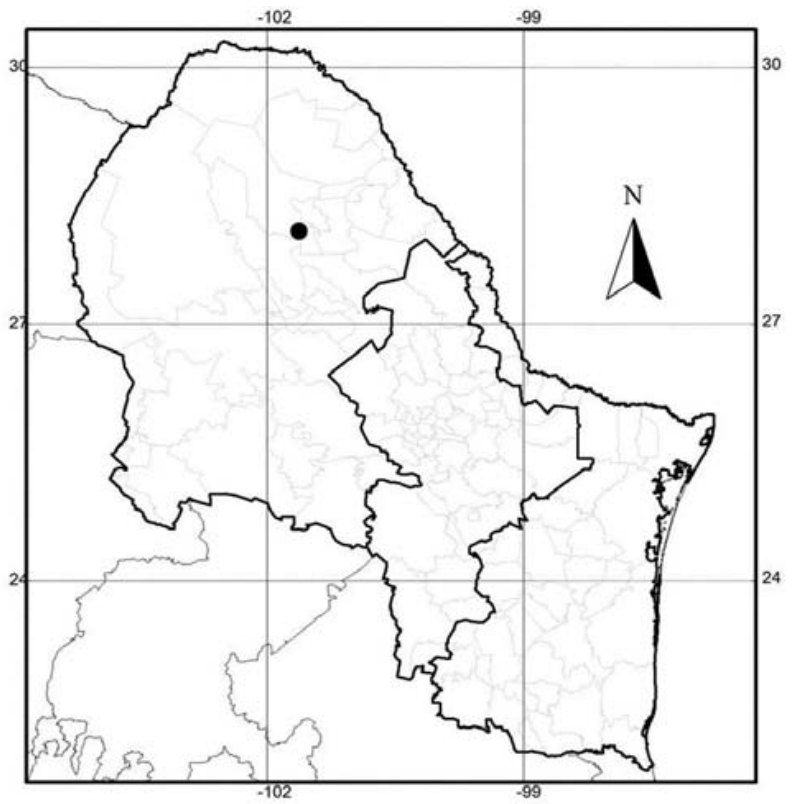

Figura 16. Distribución de • Panicum rigidulum en el Noreste de México. 
glaucas, base redondeada a subcordada, el ápice agudo, las láminas basales rizadas. Panículas terminales de $15-40 \mathrm{~cm}$ de largo, laxas y difusas, multifloras, exertas, pedúnculos hasta de $50 \mathrm{~cm}$ de largo; eje principal ligeramente ondulado, escabroso, pulvínulos glabros; ramificaciones de primer orden de $7-18 \mathrm{~cm}$ de largo, alternas u opuestas, ascendentes a divaricadas; pedicelos claviformes de 4-15 mm de largo; espiguillas ovoides, de 1.8-2.2 $\mathrm{mm}$ de largo por 0.7-1 $\mathrm{mm}$ de ancho, glabras, ascendentes, agudas a acuminadas, pálidas o con tintes violáceos hacia el ápice, gluma superior y lema inferior subyúgales, tan largas como el flósculo superior; gluma inferior de 1-1.2 mm de largo, 1/2 del largo de la espiguilla, 5(-7)-nervia, aguda; gluma superior de 1.8-1.9 (-2) mm de largo, 7-13-nervia; lema inferior igual o subigual al largo de la segunda gluma, 7-9-nervia; pálea inferior lanceolada, de 1-1.2 mm de largo, 3/5 del largo de la lema inferior, hialina, escabriúscula en las quillas, erosa; flor inferior ausente; flósculo superior ovoide, de 1.5-2 mm de largo por 0.6-1 mm de ancho, subagudo, tan largo como la lema inferior, endurecido, glabro, liso, con dos cicatrices de $0.2 \mathrm{~mm}$ de largo en la base; lema 7-nervia, pálea papilosa en el ápice; estambres 3, anteras de 0.8-1 mm de largo, púrpuras; cariopsis ovoide, de $1 \mathrm{~mm}$ de largo por $0.5 \mathrm{~mm}$ de ancho, blanquecina; hilo punctiforme, embrión 1/2 del largo de la cariopsis.

Ecología, distribución y usos: Habita en matorral mediano subperennifolio, llegando hasta los $350 \mathrm{~m}$. Florece de mayo a diciembre endémica a México.

Material examinado: MÉXICO. SAN LUIS POTOSÍ: El Banito, 100 ft, 22 Jul 1939, Chase 7558 (US); Mun. El Pujal, Chase 7492

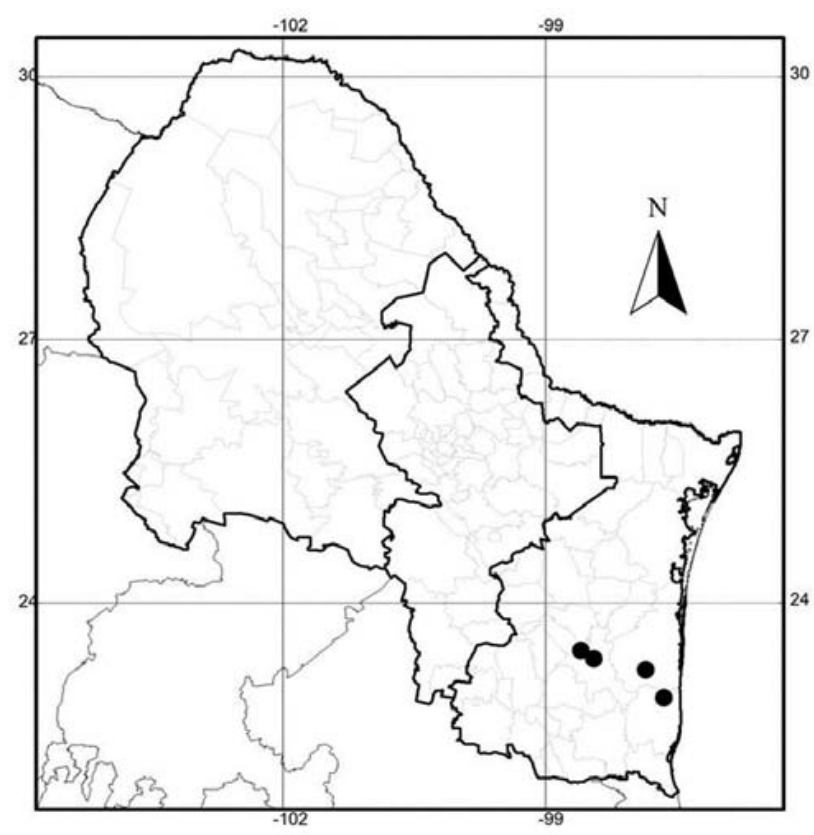

Figura 17. Distribución de • Panicum tamaulipense en el Noreste de México.
(US), 2 miles S of Huichihoayan, Mc Gregor et al. 870* (US), Ciudad Valles, 5 Mayo 1962, Beetle M-718 (US); Valles, $800 \mathrm{ft}, 17$ Jul 1933, Fischer 3313 (US); in a tropical forest along Mexico Highway 55 to Xilitla, Sohns 1431 (US). TAMAULIPAS: El Mante to Limón, 3 May 1931, Swalen 1618 (US); 64 km from Soto La Marina on the road to Casas and Victoria, 350 m, 4 Oct 1956, Martínez. Martínez \& Borja Luyando F-2364 (US); $35 \mathrm{~km}$ from Victoria on the road to Casas and Soto La Marina, 280 m, 3 Oct 1956, Martínez Martínez \& Borja Luyando F-2333* (US); $5 \mathrm{mi} \mathrm{N}$ of San Rafael toward Soto la Marina, $800 \mathrm{ft}, 11$ DIc 1959, Crutchfield \& Johnston 4956 (MEXU) (figura 17).

16. Panicum trichanthum Nees, Fl. Bras. Enum. Pl. 2: 210-212. 1829. Tipo: México, sin localidad, Humboldt \& Bonpland s.n. (lectotipo: designado por Hitchcock \& Chase, 1910, B-W!).

Plantas perennes, cortamente rizomatosas, con culmos hasta de $1.50(-2) \mathrm{m}$ de largo por $1.5 \mathrm{a} 2 \mathrm{~mm}$ de ancho, ramificados en los nudos inferiores, luego erectos; entrenudos de 2$10 \mathrm{~cm}$ de largo, cilíndricos, glabros, huecos o semi-sólidos, herbáceos o subleñosos, pajizos o con tintes violáceos; nudos contraidos, glabros, los inferiores enraizados, violáceos; vainas de 1.7-8.5 cm de largo, más cortas que los entrenudos, glabras, los bordes membranáceos, corta a largamente pilosos hacia la porción superior; lígulas membranáceas, de 0.2-0.5 mm de largo; seudolígulas con pelos de hasta 2.5 mm de largo; collar castaños, glabro a ralamente piloso; láminas lanceoladas, de 6-11 (-15) cm de largo por 0.3-2.3 cm de ancho, planas, glabras o con pelos suaves y adpresos en ambas superficies, de base subcordada a cordada, cortamente seudopecioladas, seudopecíolo castaño, los bordes escabrosos y esparcidamente pilosos. Panículas terminales exertas, de (10-) 16-31 cm de largo por 6-26 cm de ancho, laxas, difusas, multifloras, pedúnculo cilíndrico, glabro, de $15 \mathrm{~cm}$ de largo; eje princicpal glabro, liso, pulvínulos pilosos a glabros, castaños; ramificaciones de primer orden de 2-18 cm de largo, alternas, raro opuestas, divergentes y distanciadas, ejes de las ramificaciones escabriúsculos; pedicelos solitarios, largos, hasta de $15 \mathrm{~mm}$ de largo; espiguillas elipsoides, de 1-1.8 $\mathrm{mm}$ de largo por 0.5-0.9 mm de ancho, glabras, verde oscuras, gluma superior y lema inferior brillantes, con diminutas vesículas en toda su superficie; gluma inferior de 0.2-0.4 mm de largo, 1/4 o menos del tamaño de la espiguilla, enervia, obtusa a truncada; gluma superior de 1.2-1.6 mm de largo, 5-nervia, con nervios poco manifiestos; lema inferior glumiforme, 0.2-0.5 mm más corta que la segunda gluma o de igual tamaño, 3-5-nervia; pálea inferior ovado-lanceolada, de $0.6-1 \mathrm{~mm}$ de largo por $0.2 \mathrm{~mm}$ de ancho, glabra, hialina; flor inferior ausente; flósculo superior elipsoide, de 1.3-1.6 mm de largo por 0.5-0.8 $\mathrm{mm}$ de ancho, glabro, liso, lustroso y pajizo, castaño a la madurez; lema 5nervia; estambres 3, anteras de 0.5-0.7 $\mathrm{mm}$ de largo, pajizas o pardas; cariopsis obovoide, de $0.7-1 \mathrm{~mm}$ de largo por 0.6$0.8 \mathrm{~mm}$ de ancho, blanquecina; hilo obovado, embrión 1/2 del largo de la cariopsis. $\mathrm{n}=18$. 
Ecología, distribución y usos: Crece en ambientes húmedos y sombríos, en bordes de arroyos o en el sotobosque, también en potreros del matorral mediano subperennifolio, entre 70 a 500 (-900) m. Ampliamente distribuída desde México hasta Argentina.

Material examinado: MÉXICO. CAMPECHE: Ejido Pach-wits, $32 \mathrm{~km} \mathrm{~S}$ of Xmaben on the dirt road from Hopelchén to Xpujil, $1^{\circ} 00^{\prime} \mathrm{N}, 8^{\circ} 20^{\prime} \mathrm{W}, 200$ m, 12 Mar 1990, Sanders et al. 9687 (MO). CHIAPAS: Mun. of Ocozocoautla de Espinosa, large marsh and adjacent slopes, $13 \mathrm{~km}$ south of Ocozocoautla, $900 \mathrm{~m}$, 29 Oct 1981, Breedlove \& Davidse 54051 (MO); $5 \mathrm{~km} \mathrm{NW}$ of Tumbo, roadside, $17^{\circ} 06^{\prime} \mathrm{N}, 91^{\circ} 39^{\prime} \mathrm{W}, 620$ m, 26 Sep 1988, Stevens \& Martínez 25887 (MO); en Arroyo Agua Azul, a 3 km al W de Frontera Corozal, 200 m, 1 Nov 1985, Martínez 14651 (MO); Río Lacantum, on riverbank, 9 Feb 1964, Lundell 17857 (MEXU). OAXACA: Chiltepec, Tuxtepec, 23 Ago 1965, Martínez Calderón 221 (MEXU). SAN LUIS POTOSÍ: Camp area at El Salto, 1 Sep. 1972, Gallian \& Leake 1067 (MO); valley of Río Tampaon, 20 Jul 1939, Chase 7518 (MO); Tamasopo, 1200 ft, 24 Ago 1937, Fisher s.n. (MO). TABASCO: $1 \mathrm{~km}$ al $\mathrm{N}$ de Monte Grande, orilla de camino, junto canal de agua, 13 Mar 1983, Fernández et al. 1485 (MO). TAMAULIPAS: Municipio de Soto la Marina, Rancho La Feria, Cervera-Rosado Miguel H. 83 (MEXU). VERACRUZ: south edge of Tesechoacán, W side of Río Tesechoacán, $18^{\circ} 07^{\prime} \mathrm{N}$, 95³9’W, 50 m, 6 Dic 1981, Nee 23829 (MO);Tlaliscoyán, “zacate sereno", 24 Nov 1967, Martínez Calderón 1565 (MEXU, MO); Estación Biológica San Andrés Tuxtla, 7 Nov 1968, Martínez Calderón 1786 (MEXU, MO); Veracruz, Gouin 19 (P); km 6 carretera Misantla Naolinco, 520 m, 30 Ene 1976, Avendaño et al. 112 (MEXU) (figura 18).

17. Panicum trichidiachne Döll, Fl. Bras. 2:339, pl. 49. 1877. Tipo: Brasil, Rio de Janeiro, 4 Ene 1875, Glaziou 6979 (holotipo: P!, isotipos: K!, US-81150!, fragmento, ex P). Panicum schmitzii Hack., Ann. K.K. Naturhist. Hofmus. 17: 254. 1902. Tipo: México: sin localidad, sin fecha, Schmitz s.n. (holotipo: W!; isotipo: US-80974!, fragmento ex W). Panicum schiffneri Hack., Ergebn. Bot. Exp. Südbras. 1: 11. 1906. Tipo: Brasil. Sao Paulo, ca. 500 m, Jul 1901, R.R. von Wettstein \& V.F. Schiffner s.n. (holotipo: W!; isotipo: US-81102!, fragmento ex W).

Plantas perennes, con culmos rastreros a decumbentes en la base, geniculados y arraigados en los nudos inferiores, luego ascendentes a erectos, con culmos de $0.2-1.20 \mathrm{~m}$ de largo, ramificados; entrenudos cilíndricos a comprimidos, glabros o con pelos largos blanquecinos adpresos y escasos; nudos oscuros y con pelos blanquecinos, los inferiores enraizándose; vainas de $2-10 \mathrm{~cm}$ de largo, híspidas a glabrescentes, los bordes cortamente pestañosos; lígulas membranáceo-ciliadas de 0.2-0.9 mm de largo; cuello piloso, oscuro; láminas ovado-lanceoladas a lanceoladas, de (5-) 11-14 (-17) cm de largo por 10-20 (-31) mm de ancho, planas, glabras a estrigosas en la superficie adaxial, glabras a pilosas con el nervio medio hirsuto en la abaxial, de base estrecha, asimétrica y seudopeciolada, los bordes escabrosos. Panículas terminales de (3-) 7-14 (-18) cm de largo, terminal, laxa, pauciflora; eje principal anguloso, escabroso, hirsuto a glabro, pulvínulos castaños, pilosos; ramificaciones de primer orden de 2-4 cm de largo, opuestas o alternas, ascendentes a divaricadas, desnudas en la base; ejes de las ramificaciones glabros a hirsutos, espiguillas apretadas en las ramas y solitarias sobre pedicelos cortos, escabrosos; espiguillas elipsoides, de 1.6-1.9 (-2.2) $\mathrm{mm}$ de largo por 0.8-1 mm de ancho, glabras, verdosas, obtusas, gluma superior y lema inferior subyúgales y con nervios marcados; gluma inferior de 0.3-0.5 mm de largo, 1/5 del largo de la espiguilla, enervia o uninervia, hialina, aguda a obtusa; gluma superior de 1.6-1.9 (-2.2) mm de largo, 5-7-nervia; lema inferior ligeramente más corta que la segunda gluma, 5-nervia; pálea y flor inferior ausentes; flósculo superior elipsoide, de (1.3-) 1.5-1.8 mm de largo, por 0.7-0.9 mm de ancho, con pelos blanquecinos adpresos, diminutamente papiloso, brillante, elipsoide, subagudo a obtuso; estambres 3 , anteras de casi $0.5 \mathrm{~mm}$ de largo; cariopsis ampliamente elipsoide, de $1.1 \mathrm{~mm}$ de largo por $0.8 \mathrm{~mm}$ de ancho; hilo punctiforme, embrión menos de la mitad del largo de la cariopsis. $\mathrm{n}=18$.

Ecología, distribución y usos: Crece en lugares húmedos y sombreados en los límites de los bosques, desde el nivel del mar hasta los $2800 \mathrm{~m}$. Ampliamente distribuída desde Mesoamérica y el Caribe hasta Sudamérica.

Material examinado: MÉXICO. CHIAPAS: Las Margaritas, 12 $\mathrm{km}$ E of Tziscao, along carretera fronteriza, 1200-1300 m, 16 Nov 1984, Davidse et al. 29888 (MEXU, MO, SI), Mpio. Ocosingo, 6-8 km north of Ocosingo along road to Bachajón, 900 m, 24 Sep

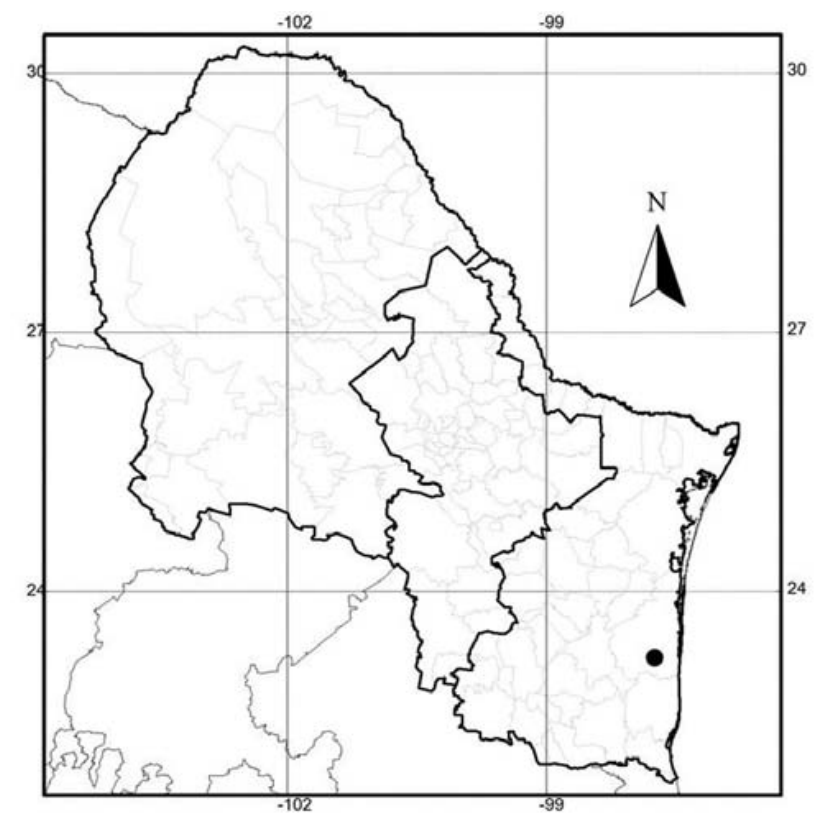

Figura 18. Distribución de • Panicum trichanthum en el Noreste de México. 
1972, Breedlove 27948 (MO), Mpio., Ocozocoautla de Espinosa, $32 \mathrm{~km}$ northwest of Ocozocoautla, $600 \mathrm{~m}, 27$ Ago 1972, Breedlove 27484 (MO); San Fernando, 4-6 km W of Mirador Los Chiapas in Parque Nacional del Sumidero, 1180-1240 m, 14 Nov 1984, Davidse et al. 29743 (MEXU, MO, SI); Sierra Madre, Tateoka 1028 (US); Mun. of Tuxtla Gutiérrez, $22 \mathrm{~km}$ north of Tuxtla Gutiérrez, 13 Nov 1981, Breedlove \& Davidse 55483 (MO); on the southeast side of Volcán Tacana above Talquian, 2200 m, 12 Nov 1972, Breedlove 29490 (MEXU, MO). HIDALGO: Carretera Panamericana, km 341, N of Chapulhuacan, Moore Jr. 1327 (US). SAN LUIS POTOSI: Barranca de Las Canoas, 18 Ago 1891, Pringle 3817 (F, GH, MEXU, MO, NY, US); $55 \mathrm{~km}$ of Xilitla, Sohns 1450 (US); in a tropical forest between Narango-Platinilto-Salto de Agua, 400-600 m, 22 Sep 1954, Sohns 1397 (MEXU). TAMAULIPAS: Camino al Rancho El Cielo, 15 Sep 1990, Crespo 384 (ANSM); aproximadamente a $3 \mathrm{~km}$ del Ejido Alta Cima rumbo al Ej. San José, Gómez Farías, 10 Nov 1990, Crespo 492 (ANSM); a un costado del panteón en Gómez Farías, 14 Oct 1990, Crespo 436 (ANSM). VERACRUZ: Cordoba, Bourgeau 1662 (US), 900 m, Hitchcock 6423 (US), 6459 (MO, NY, US); Rio Blanco, near Orizaba, 1200-1400 m, Hitchcock 6383 (MO, NY, US); $1.8 \mathrm{~km} \mathrm{SSE} \mathrm{of} \mathrm{El} \mathrm{Mirador} \mathrm{and}$ turnoff from the Totutla-Conejos highway, $950-1000 \mathrm{~m}, 19^{\circ} 12^{\prime} \mathrm{N}$, 9651'W, 21 Nov. 1981, Nee y Cortés 23363 (MO) (figura 19).

18. Panicum trichoides Sw., Prodr.: 24. 1788. Tipo: Jamaica: sin localidad, Swartz s.n. (lectotipo: designado por Hitchcock, 1908, S!; isotipo: US-81153!, fragmento ex S). Plantas anuales, estoloníferas, decumbentes y arraigadas en los nudos, culmos erguidos de $10-60 \mathrm{~cm}$ de alto por $0.5-1$ (-2) mm de ancho, libremente ramificados; entrenudos pilosos, huecos; nudos oscuros, pilosos, con pelos cortos, los inferiores enraizándose; vainas generalmente más cortas que los entrenudos, densa a esparcidamente papiloso-híspidas,

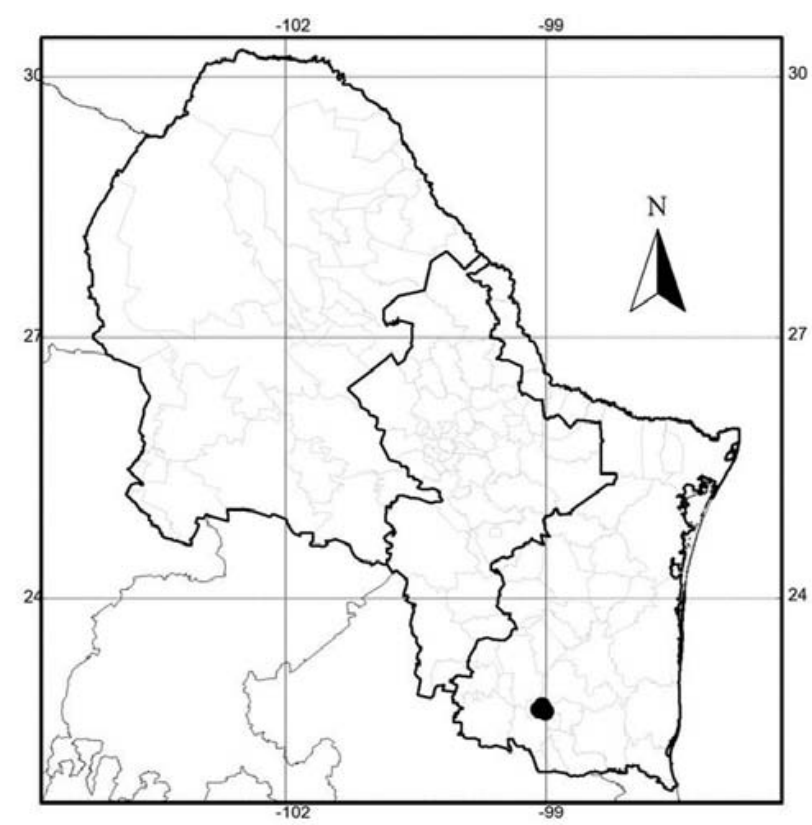

Figura 19. Distribución de • Panicum trichidiachne en el Noreste de México. los márgenes ciliados; lígulas membranáceas de 0.2-0.5 mm de largo, cortamente ciliadas en la porción superior; collar piloso; láminas ovado-lanceoladas, de $1.5-9 \mathrm{~cm}$ de largo por 0.5-2 cm de ancho, planas, glabras a hirsuto-papilosas, de base cordada a subcordada a asimétrica, con pelos papiloso-híspidos en los márgenes. Panículas terminales, ocasionalmente axilares, de 4-24 cm de largo, terminal y a veces axilares presentes, laxas, difusas, subincluídas o exertas, pedúnculo hasta de $5 \mathrm{~cm}$ de largo; eje principal hirsuto a glabro, pulvínulos glabros; ramificaciones de primer orden de 1-6.5 $(-10) \mathrm{cm}$ de largo, alternas, ascendentes a reflexas, ejes de las ramificaciones glabros o papiloso-híspidos, escabrosos; espiguillas obovoides a elipsoides, de 0.9-1.5 $\mathrm{mm}$ de largo por 0.5- $0.7 \mathrm{~mm}$ de ancho, plano-convexas, hirsutas a veces papilosas, ascendentes a divaricadas, subagudas a obtusas; gluma inferior de $0.4-1 \mathrm{~mm}$ de largo, de 1/2 a 1/3 del tamaño de la espiguilla, 1-3-nervia, subaguda; gluma superior de 0.8-1.2 mm de largo, 3-5-nervia; lema inferior glumiforme, 3-5-nervia, aguda; pálea inferior de 0.5-0.8 mm de largo, $1 / 3$ a 1/2 del tamaño de la lema inferior, lanceolada, glabra o con pelos escasos y cortos en las quillas, hialina; flor inferior ausente; flósculo superior ovoide, de 0.8-1.3 $\mathrm{mm}$ de largo por 0.4-0.6 mm de ancho, pajizo, lustroso, transversalmente rugoso y con micropelos bicelulares, agudo, sobre un estípite de aproximadamente $0.2 \mathrm{~mm}$; estambres 3 , anteras de 0.3-0.6 mm de largo; cariopsis anchamente elipsoide, de 0.7-0.9 mm de largo por 0.3-0.5 mm de ancho, blanca; hilo punctiforme, embrión menos de la mitad del largo de la cariopsis. $\mathrm{n}=9,18$.

Ecología, distribución y usos: Habita en pastizales, matorrales xerófilos, selvas bajas, medianas y altas, encinares, bosques de pino-encino, vegetación riparia, en caminos y cafetales, desde el nivel del mar hasta 1900 m. Florece de junio a diciembre. Distribuída desde Estados Unidos hasta Argentina.

Nombre común: "zacate carricillo".

Material examinado: TAMAULIPAS: Municipio de Tula, Puerto de La Virgen, Brito Alfredo 49 (MEXU) (figura 20).

19. Panicum virgatum L., Sp. P1. 1: 59. 1753. Tipo: "Gramen miliaceum alluv. maritimum foliis arundinis", Clayton 578 (lectotipo: designado por Hitchcock, 1908, BM!; isolectotipo: US!, fragmento ex BM). Panicum ichnanthoides E. Fourn., Mexic. Pl. 2: 30. 1886. Tipo: México, Veracruz, Orizaba, Muller 2002 (holotipo: LE!; isotipo: US-80702!, fragmento ex LE).

Plantas perennes, rizomatosas, con rizomas, fuertes, culmos erectos de 0.4-2 (-3) $\mathrm{m}$ de largo por 3 a $5 \mathrm{~mm}$ de diámetro, simples, con multiples nodos, subleñosos a leñosos; entrenudos cilíndricos, los inferiores sólidos, huecos hacia la porción superior, escabriúsculos, glaucos; nudos glabros, 


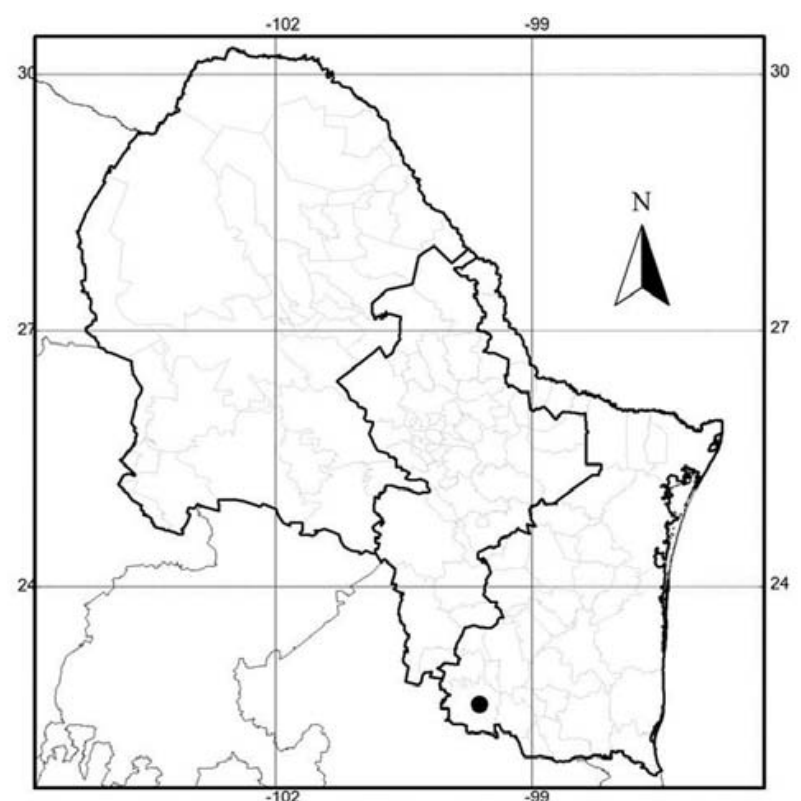

Figura 20. Distribución de - Panicum trichoides en el Noreste de México.

castaños; vainas mas largas que los entrenudos inferiores y más cortas que los superiores, glabras o a veces pilosas, redondeadas, pajizas o con tintes violáceos; lígulas membranáceo-ciliadas de 1.5-4.5 mm de largo, porción membranácea corta; collar glabro o piloso; láminas lanceoladas a linear-lanceoladas, de $10-60 \mathrm{~cm}$ de largo por $3-15 \mathrm{~mm}$ de ancho, planas, linear, glabras o pubescentes, a veces con vellos densos en la superficie adaxial y hacia la zona ligular y la garganta, base redondeada o ligeramente angosta, los márgenes escabrosos. Panículas terminales de $15-55 \mathrm{~cm}$ de largo, multifloras, laxas y difusas a contraidas, exertas, con pedúnculo liso, glabro, cilíndrico; eje principal cilíndrico, glabro, pulvínulos pilosos o glabros; ramificaciones de primer orden divergentes del eje principal, alternas u opuestas, de 4$20 \mathrm{~cm}$ de largo, ascendentes a divaricadas, ejes de las ramificaciones angulosos, escabrosos, espiguillas dispersas en las ramas sobre pedicelos claviformes, escabrosos; espiguillas lanceoladas de 3.3-5(-6) $\mathrm{mm}$ de largo por 1.2-2 $\mathrm{mm}$ de ancho, glabras, abiertas a la madurez, acuminadas, gluma superior y lema inferior subiguales, superando en ca. $0.9 \mathrm{~mm}$ al flósculo superior; gluma inferior de 1.8-3.2 mm de largo, 1/2 a 4/5 del largo de la espiguilla, (5-) 9-nervia, acuminada, cortamente pilosa en la cara interna; gluma superior de (3)3.3-5 mm de largo, 7-11-nervia; lema inferior glumiforme, 7-9-nervia; pálea inferior largamente elíptica, de 3-3.2 mm, de 4/5 a tan larga como la lema inferior, oblongo-lanceolada, quillas glabras, diminutamente erosa; flor inferior estaminada, anteras de 1-2.9 mm de largo; flósculo superior largamente ovoide, de 2.3-3 mm de largo por 0.8-1.1 mm de ancho, tempranamente decíduo, endurecido, glabro, liso, subagudo, pajizo a oliváceo a la madurez; lema 7-nervia, estambres 3, anteras de 1.7-2 mm de largo, pardas; cariopsis de contorno oblongo, oliváceo; hilo oblongo, embrión poco más de $1 / 2$ del largo de la cariopsis. $n=9,10,15,18,27,36$, $45,54,66-72,74,77$.

Ecología, distribución y usos: Crece en laderas de cerros, cañadas, praderas, ciénagas, lechos de ríos, claros de bosque de encino, de pino-encino, desde el nivel del mar hasta los 1900 m. Florece de junio a octubre. Distribuída desde el sur de Canadá a México, Mesoamérica y el Caribe. Su valor forrajero es bueno, se utiliza como heno si se corta en prefloración. Se utiliza para combatir la erosión del suelo y como medicinal para tratar neumonías.

Nombre común: "Itse'toom".

Material examinado: MÉXICO. Chiapas: Hacienda Monserrat, Sep 1923, Purpus 9199 (MO, US); Chismanta, Sabana Palenque, Jul 1939, Matuda 3722 (F, MEXU, US); Union del rio Perlas y el rio Jatate, cerca de la laguna Miramar, Sohns 1566 (US); near the $99 \mathrm{~km}$ post E of Villahermosa on the Villahermosa-Francisco Escárcega road, 9 Ago 1975, Davidse \& Davidse 9396 (MO); Mun. La Trinitaria, Lagos de Montebello, $42 \mathrm{~km}$ northeast of La Trinitaria, 1300 m, 23 Oct 1971, Breedlove \& Thorne 21270 (MEXU, MO); Mun. La Trinitaria, montane rain forest at Lagos de Colores, Lagos de Montebello National Park, 1370 m, 7 Nov 1981, Breedlove \& Davidse 55039 (MO). COAHUILA: $28 \mathrm{~km}$ al norte de Zaragoza, pasando rancho La Salada en Rio San Rodrigo, 22 Sep 1977, Valdes Reyna 1280 (MEXU). JALISCO: Zapopan, entre Zapopan y Sapiquipan, Oliva 49 (US); Río Blanco, 1886, Palmer 510 (MEXU, MO); $2 \mathrm{~km}$ al S de San Antonio de Padua, 10 Aug 1986, Santana Michel et al. 1850 (MEXU). NUEVO LEÓN: Rio Ra-

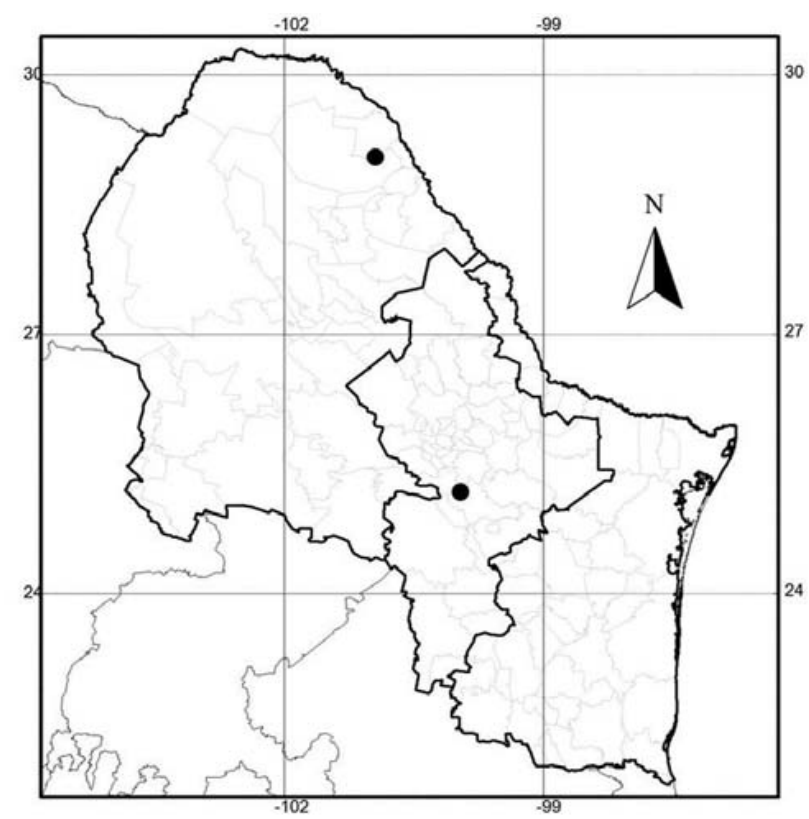

Figura 21. Distribución de • Panicum virgatum en el Noreste de México. 
mos, 4 km al sur de Allende, 14 Jul 1983, Valdes Reyna 1548 (MEXU). PUEBLA: Tehuacan, Mar 1917, Patoni s.n. (MEXU 3704). QUINTANA ROO: km 55 de Tulum a Punta Allen, vegetación de duna costera perturbada, 11 Oct 1983, Durán \& Espejel 551 (MEXU); km 9 al sureste de Chumpón, 31 Ago 1984, Durán \& Olmsted 1039 (MEXU), selva baja inundable. SAN LUIS POTOSÍ: Laguna de la Media Luna, 980 m, Takaki s.n. (MEXU 163597). Veracruz: Orizaba, Hitchcock 6364 (US); about 8 miles north of Ciudad Alemán, 120 m, 16 Ago 1953, Reeder \& Reeder 1996 (MEXU). Sin localidad, Oliva 78 (US) (figura 21).

\section{Agradecimientos}

Juan Encina Domínguez, Sergio Germán Gómez Pérez, Efrén Mata Rocha y Miguel Agustín Carranza Pérez por el apoyo otorgado en la captura de información y la elaboración de los mapas. A la Comisión Nacional para el Conocimiento y Uso de la Biodiversidad (CONABIO), a través del proyecto G029 “Gramíneas del Noreste de México”.

\section{Literatura citada}

Aliscioni S.S., Giussani L.M., Zuloaga F.O. y Kellogg E.A. 2003. A molecular phylogeny of Panicum (Poaceae: Paniceae): tests of monophyly and phylogenetic placement within the Panicoideae. American Journal of Botany 90: 796-821.

Barkworth M.E. 2004. Manual of grasses for North America and North of Mexico. University of Utah, Logan. (http://herbarium. usu.edu/webmanual/).

Bess E.C., Doust A.N., Davidse G. y Kellogg E.A. 2006. Zuloag$a e a$, a new genus of neotropical grass within the "Bristle Clade" (Poaceae: Paniceae). Systematic Botany 31: 656-670.

Duvall M.R., Noll J.D. y Minn A.H. 2001. Phylogenetics of Paniceae (Poaceae). American Journal of Botany 88: 1988-1992.

Freckmann R.W. y Lelong M.G. 2003. Nomenclatural changes and innovations in Panicum and Dichanthelium (Poaceae: Paniceae). Sida 20: 161-174.

Giussani L.M., Cota-Sánchez J.H., Zuloaga F.O. y Kellogg E.A. 2001. A molecular phylogeny of the grass subfamily Panicoideae (Poaceae) shows multiple origins of $\mathrm{C}_{4}$ photosynthesis. American Journal of Botany 88: 1993-2012.
Gómez-Martínez R. y Culham A. 2000. Phylogeny of the subfamily Panicoideae with emphasis on the tribe Paniceae: evidence from the trnL-F cpDNA region. En: Jacobs, S.W.L. y Everett J.E. Eds., Grasses: systematics and evolution, pp. 136-140, Victoria, Collingwood: Commonwealth Scientific and Industrial Research Organization (CSIRO) Publishing.

Linnaeus C. 1753. Panicum. Species Plantarum 1: 55-59. Stockholm. (Fascimile edition: London, 1957).

Morrone O., Denham S.S., Aliscioni S. y Zuloaga F.O. 2008. Parodiophyllochloa, a new genus segregated from Panicum (Paniceae, Poaceae) based on morphological and molecular data. Systematic Botany 33: 66-76.

Simon B.K. y Jacobs S.W.L. 2003. Megathyrsus, a new generic name for Panicum subgenus Megathyrsus. Austrobaileya 6: 571-574.

Rzedowski J. 1994. Vegetación de México. Editorial Limusa, S.A. de C.V. México. 432p.

Webster R.D. 1988. Genera of the North American Paniceae (Poaceae: Panicoideae). Systematic Botany 13:576-609.

Zuloaga F.O. 1987. Systematics of new world species of Panicum (Poaceae: Paniceae). En: Soderstrom T.R., Hilu K.W., Campbell C.S. y Barkworth M.E. Eds., Grass Systematics and Evolution, pp. 287-306, Washington, D.C.: Smithsonian Institution Press.

Zuloaga F.O., Morrone O. y Giussani L.M. 2000. A cladistic analysis of the Paniceae: a preliminary approach. En: Jacobs S.W.L. y Everett J.E. Eds., Grasses: Systematics and Evolution, pp. 123-135, Victoria, Collingwood: Commonwealth Scientific and Industrial Research Organization (CSIRO) Publishing.

Zuloaga F.O., Morrone O., Vega A.S. y Giussani L.M. 1998. Revisión y análisis cladístico de Steinchisma (Poaceae: Panicoideae: Paniceae). Annals of the Missouri Botanical Garden $\mathbf{8 5}$ : 631-656.

Zuloaga F.O., Morrone O., Davidse G., Filgueiras T.S, Peterson P.M., Soreng R.J. y Judziewicz E.J. 2003. Catalogue of new world grasses (Poaceae): III. Subfamilies Panicoideae. Aristidoideae, Arundinoideae, and Danthonioideae. Contributions from the United States National Herbarium 46:7-662.

Zuloaga F.O., Giussani, L. y Morrone O. 2007. Hopia, a new monotypic genus segregated from Panicum (Poaceae). Taxon 56: $145-156$. 